\title{
Reduced Calreticulin Levels Link Endoplasmic Reticulum Stress and Fas-Triggered Cell Death in Motoneurons Vulnerable to ALS
}

\author{
Nathalie Bernard-Marissal, ${ }^{1,2}$ Anice Moumen, ${ }^{1,2}$ Claire Sunyach, ${ }^{1,2}$ Christophe Pellegrino, ${ }^{2,3}$ Keith Dudley, ${ }^{1,2}$ \\ Christopher E. Henderson, ${ }^{4}$ Cédric Raoul, ${ }^{1,2}$ and Brigitte Pettmann ${ }^{1,2 *}$ \\ ${ }^{1}$ INSERM-Avenir team, The Mediterranean Institute of Neurobiology, 13273 Marseille, France, ${ }^{2}$ Université de la Méditerranée, UMR S901, 13009 France, ${ }^{3}$ \\ The Mediterranean Institute of Neurobiology, INMED, Marseille Cedex 09, France, and ${ }^{4}$ Center for Motor Neuron Biology and Disease, Columbia Stem Cell \\ Initiative, Departments of Pathology, Neurology, and Neuroscience, Columbia University Medical Center, New York, New York 10032
}

Cellular responses to protein misfolding are thought to play key roles in triggering neurodegeneration. In the mutant superoxide dismutase (mSOD1) model of amyotrophic lateral sclerosis (ALS), subsets of motoneurons are selectively vulnerable to degeneration. Fast fatigable motoneurons selectively activate an endoplasmic reticulum (ER) stress response that drives their early degeneration while a subset of mSOD1 motoneurons show exacerbated sensitivity to activation of the motoneuron-specific Fas/NO pathway. However, the links between the two mechanisms and the molecular basis of their cellular specificity remained unclear. We show that Fas activation leads, specifically in mSOD1 motoneurons, to reductions in levels of calreticulin (CRT), a calcium-binding ER chaperone. Decreased expression of CRT is both necessary and sufficient to trigger SOD1 ${ }^{\mathrm{G} 93 \mathrm{~A}}$ motoneuron death through the Fas/NO pathway. In SOD1 ${ }^{\mathrm{G} 93 \mathrm{~A}}$ mice in vivo, reductions in CRT precede muscle denervation and are restricted to vulnerable motor pools. In vitro, both reduced CRT and Fas activation trigger an ER stress response that is restricted to, and required for death of, vulnerable SOD1 ${ }^{\text {G93A }}$ motoneurons. Our data reveal CRT as a critical link between a motoneuron-specific death pathway and the ER stress response and point to a role of CRT levels in modulating motoneuron vulnerability to ALS.

\section{Introduction}

Amyotrophic lateral sclerosis (ALS) is a fatal neurodegenerative disease characterized by the selective loss of both upper and lower motoneurons in the cortex and spinal cord (Wijesekera and Leigh, 2009). Approximately $2 \%$ are familial forms caused by dominant mutations in superoxide dismutase 1 (SOD1). Transgenic mice overexpressing mutant forms of SOD1 (mSOD1) develop a motor neuron disease closely resembling ALS (Bruijn et al., 2004), reflecting both cell-autonomous and nonautonomous toxic effects of mSOD1 (Boillée et al., 2006). Although the sequence of cellular events leading to motoneuron degeneration

Received Oct. 24, 2011; revised Feb. 1, 2012; accepted Feb. 19, 2012.

Author contributions: C.E.H., C.R., and B.P. designed research; N.B.-M., A.M., C.S., C.P., K.D., and B.P. performed research; N.B.-M., C.R., and B.P. analyzed data; N.B.-M., C.E.H., C.R., and B.P. wrote the paper.

This work was supported by the Institut National de la Santé et de la Recherche Médicale (INSERM) by MNRT and Association Française contre les Myopathies (AFM) fellowships to N.B.-M. and by grants from the AFM, Association Française pour la Recherche sur la SLA (ARS), and by the European Union through the Mitotarget Consortium (contract FP7-223388).We thank all members of the Avenir team for their helpful comments throughout the work. We thank Dr. M. Michalak (University of Alberta, Canada) for the generous gift of the crt heterozygous mice as well as for helpful comments on the manuscript. We also acknowledge valuable suggestions from Dr.P. Caroni (Friedrich Miescher Institute, Switzerland).

Correspondence should be addressed to Dr. Brigitte Pettmann, INSERM-Avenir team, The Mediterranean Institute of Neurobiology, INMED, 163, route de Luminy, 13273 Marseille Cedex 09, France. E-mail: brigitte. pettmann@inserm.fr.

C. Raoul's current address: The Neuroscience Institute of Montpellier, INM, Inserm UMR1051, Saint Eloi Hospital, Montpellier, France.

DOI:10.1523/JNEUROSCI.5431-11.2012

Copyright $\odot 2012$ the authors $\quad 0270-6474 / 12 / 324901-12 \$ 15.00 / 0$ has been relatively precisely mapped (Kanning et al., 2010), the molecular pathways downstream of $\mathrm{mSOD} 1$ that regulate the specificity and timing of the disease process remain, however, to be determined.

We reported previously that purified embryonic motoneurons from mSOD1 mice display exacerbated susceptibility to death through a motoneuron-specific pathway induced by activation of the Fas/CD95 death receptor (Raoul et al., 1999, 2002). We further demonstrated that nitric oxide (NO), a downstream effector of Fas activation in motoneurons, increases the expression of FasL and thereby leads, in mSOD1 motoneurons but not in controls, to further production of NO in a vicious cycle (Raoul et al., 2006). However, the mechanism through which mSOD1 motoneurons are sensitized 10- to 100-fold to FasL/NO had not been elucidated, and it was not clear whether this was an amplification of the pathway used by wild-type (WT) neurons or whether it involved a new, disease-specific signaling pathway.

We recently used an unbiased proteomic approach to identify molecular changes that occur selectively in mSOD1 motoneurons in response to activation of the Fas/NO pathway, and therefore might explain the exacerbated sensitivity of ALS model motoneurons to Fas/NO-triggered cell death (Duplan et al., 2010). One of the very few changes detected was a twofold reduction in the levels of calreticulin (CRT). CRT is both a chaperone protein implicated in protein folding and a calciumbinding protein responsible for the storing of calcium in the 
endoplasmic reticulum (ER; Smith and Koch, 1989). Perturbations in these two functions lead to ER stress activation, an important event shown to trigger apoptosis if excessive (Breckenridge et al., 2003; Oyadomari and Mori, 2004; Rao et al., 2004) and to be involved in ALS pathogenesis (Kikuchi et al., 2006; Ilieva et al., 2007; Atkin et al., 2008).

In this work, we studied the potential role of the CRT decreased expression in a murine model of ALS. We show that motoneurons derived from mSOD 1 embryos and treated with a Fas activator present a decreased expression of CRT in vitro, and that the reduction in CRT is an integral part of the Fas/NO death pathway and is both necessary and sufficient to trigger death of ALS-mutant motoneurons. Moreover, a similar reduction occurs in vivo in presymptomatic mSOD1 mice and is restricted to vulnerable motoneuron pools. Last, reductions in CRT trigger an ER stress response that occurs only in vulnerable mSOD1 motoneurons and is sufficient to explain their exacerbated sensitivity to activation of the Fas/NO pathway. Our data reveal CRT as a critical link between the ER stress response and a motoneuron-specific cell death pathway and suggest that modulating CRT levels may in the future confer benefit in ALS patients.

\section{Materials and Methods}

Animals. All animal experiments were performed in compliance with the European and national directives for the care and use of laboratory animals. CD1 mice were purchased from The Jackson Laboratory, transgenic mice expressing mutant G85R (SOD1 ${ }^{\mathrm{G} 85 \mathrm{R}}$ ) and WT human SOD1 (SOD1 ${ }^{\text {WT }}$ ) were kindly provided by Professor D. Cleveland (University of California at San Diego) and Professor S. Przedborski (Columbia University, New York) respectively; transgenic mice for mutant G93A (SOD1 ${ }^{\mathrm{G} 93 \mathrm{~A}}$ ) were obtained from Transgenic Alliance. SOD1 ${ }^{\text {G85R }}$ (line 148) (Bruijn et al., 1997) and SOD $1^{\text {WT }}$ mice (line 76) (Wong et al., 1995) were maintained as hemizygotes by crossing transgenic males with nontransgenic females of the same C57BL/6 genetic background. SOD1 ${ }^{\text {G93A }}$ mice (line G1H) (Gurney et al., 1994) were maintained as hemizygotes by crossing transgenic males with nontransgenic females of the same B6/SJL genetic background (The Jackson Laboratory). Offspring were genotyped by separate PCRs for human SOD1 (Raoul et al., 2002), exon 3 (PCR primers: $5^{\prime}$-TTCTGTTCCCTTCTCACTGT-3' and $5^{\prime}$-TCCCCTTTGGCACTTGTATT- $3^{\prime}$ ), and exon 5 (primers $5^{\prime}$-TGTTGGGAGGAGGTAG TGATTA- ${ }^{\prime}$ and $5^{\prime}$-AGCAGAGTTGTGTTAG TTTTAG-3'). In each PCR, the mouse globin gene was amplified with primers 5-GATCATGACC GCCGTAGG and 5'-CATGAACTTGTCCCAGG CTT-3'. During the PCR for embryo genotyping
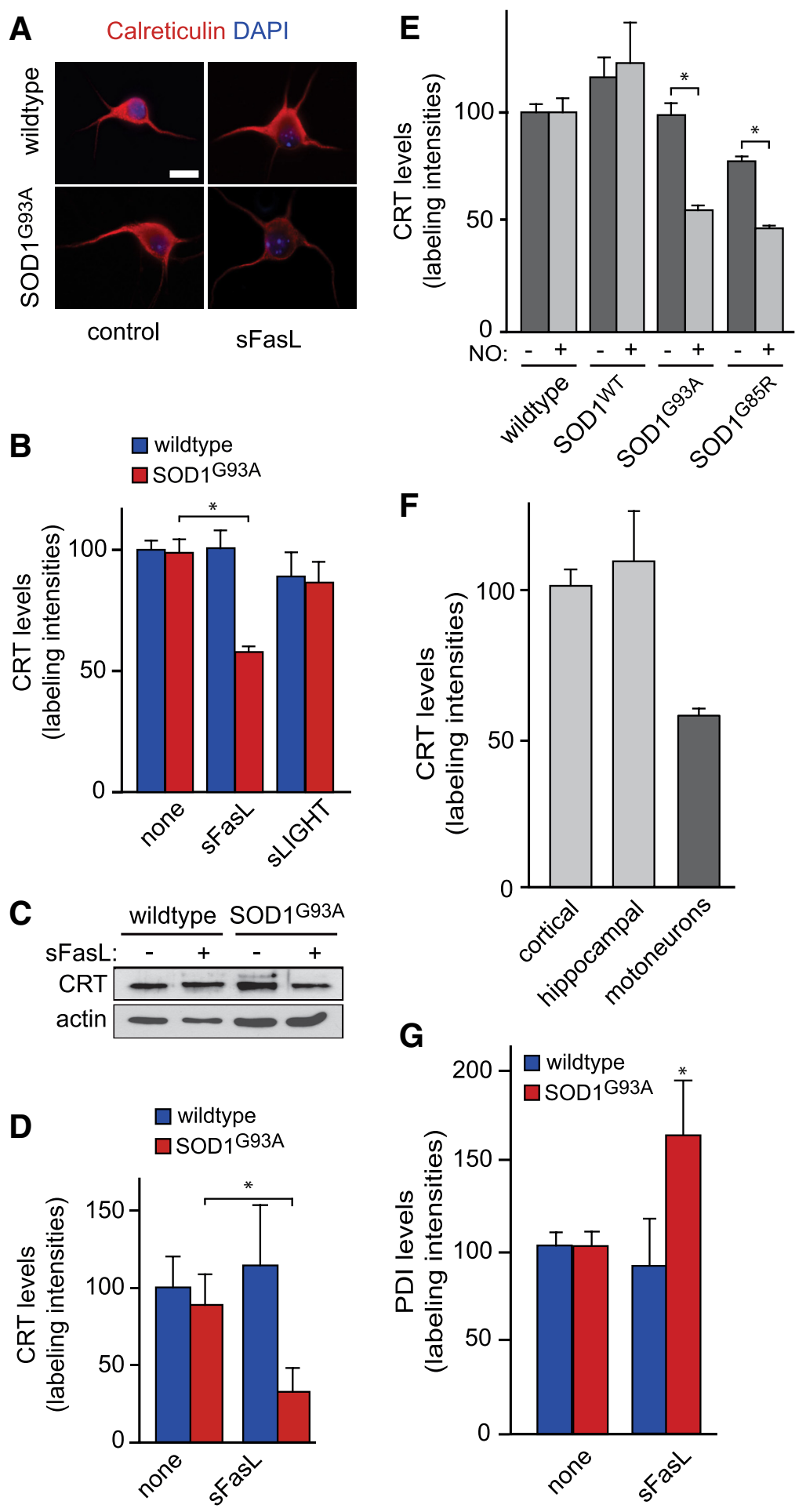

Figure 1. Expression of CRT, a luminal ER protein, is decreased twofold only in SOD $1{ }^{\mathrm{G} 93 \mathrm{~A}}$ motoneurons and only after sFasL or NO treatment. Decrease in CRT expression is Fas-dependent and happens only in SOD1 ${ }^{\text {G93A }}$ motoneurons and only after sFasL treatment. CRT staining was visualized $(\boldsymbol{A})$ and quantified $(\boldsymbol{B})$ in cells cultured for $24 \mathrm{~h}$, then treated for $24 \mathrm{~h}$ with sFasL (1 or 100 $\mathrm{ng} / \mathrm{ml}$ ) or sLIGHT (100 ng/ml). Western blots of cultured motoneuron extracts $(\boldsymbol{C})$ were quantified $(\boldsymbol{D})$, confirming the immunostaining results. CRT decreased expression occurs in motoneurons expressing different human mutated SOD1, but not in motoneurons expressing the human WT SOD1 (E). CRT fluorescence was quantified in motoneurons cultured from SOD1 ${ }^{\mathrm{G} 93 \mathrm{~A}}, \mathrm{SOD} 1^{\mathrm{G} 85 \mathrm{R}}$, and SOD $1{ }^{\text {WT }}$ embryos for $24 \mathrm{~h}$ and treated with DETANONOate, an N0 donor $(10 \mu \mathrm{M})$. CRT decreased expression is specific to motoneurons $(\boldsymbol{F})$. CRT fluorescence was quantified in motoneurons and cortical and hippocampal neurons, cultured for $24 \mathrm{~h}$, then treated for $24 \mathrm{~h}$ with $\mathrm{NO}(20 \mu \mathrm{M})$. Results are expressed as ratio to the CRT level measured in untreated cells. Scale bar, $20 \mu \mathrm{m}$. PDI, an ER stress marker shows increased expression in SOD $1^{\mathrm{G} 93 \mathrm{~A}}$ motoneurons after sFasL treatment $(\boldsymbol{G})$. PDI fluorescence was quantified after sFasL $(100 \mathrm{ng} / \mathrm{ml})$ treatment as in $\boldsymbol{B}$. The mean intensity of CRT or PDI fluorescence was assessed using NHI ImageJ software. Data are means $\pm S D$ of three independent experiments: ${ }^{*} p<0.05$. 
A

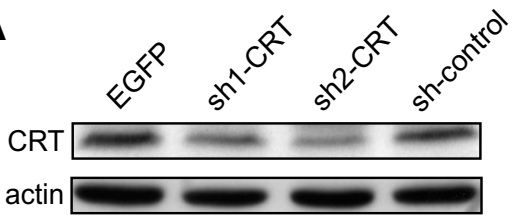

C

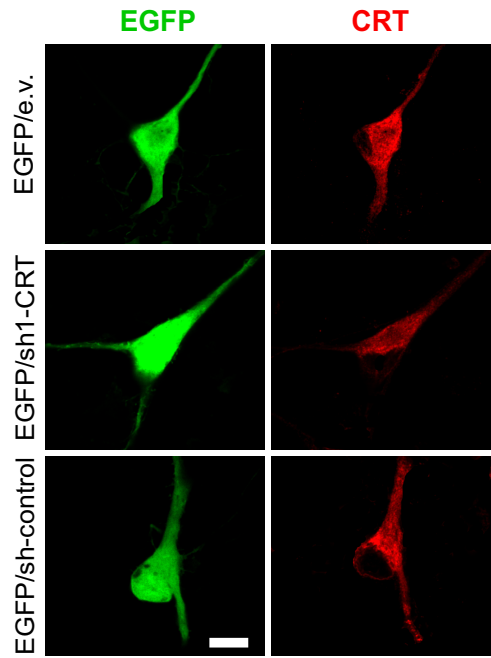

E

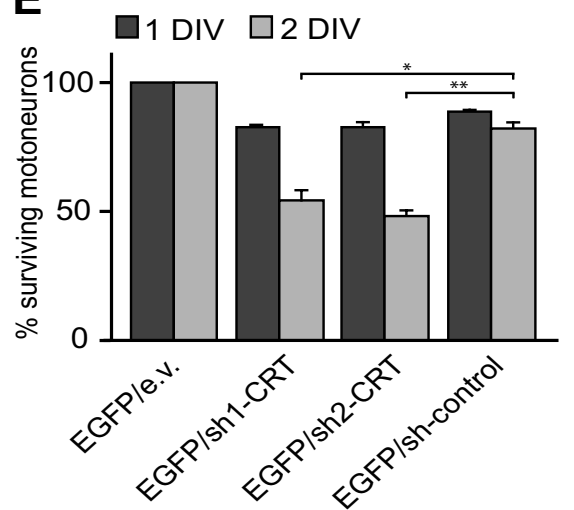

G

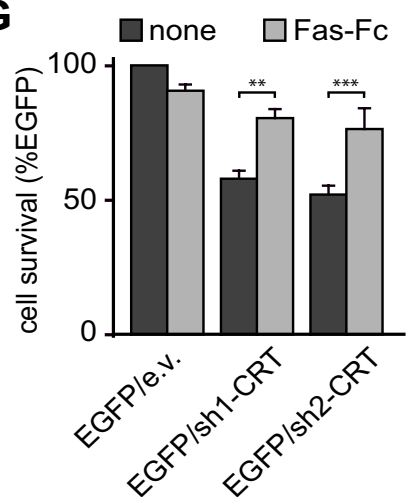

B

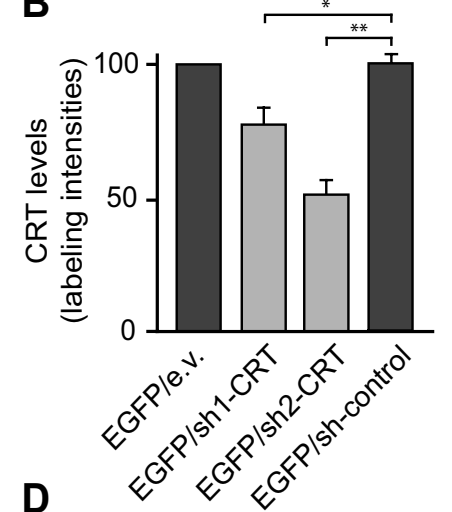

D

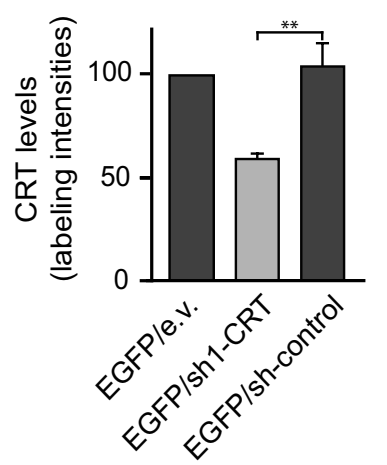

$\mathbf{F}$

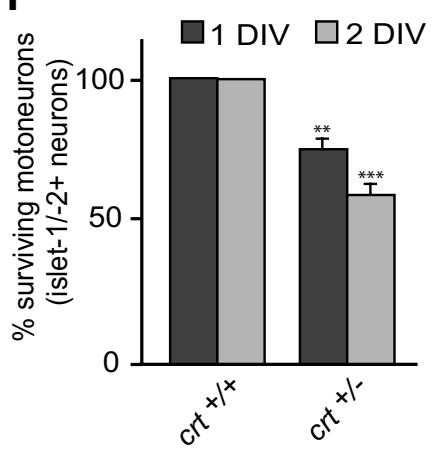

H

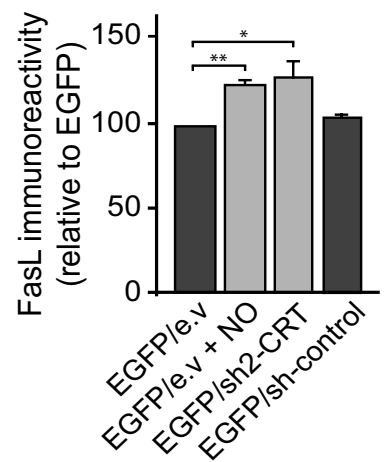

Figure 2. CRT downregulation in WT motoneurons in vitro leads to death and implicates the Fas signaling pathway. Efficiency and specificity of CRT silencing with sh-CRTs in NSC34 cells $(\boldsymbol{A}, \boldsymbol{B})$ and in motoneurons $(\boldsymbol{C}, \boldsymbol{D})$. NSC34 cells were cultured for $24 \mathrm{~h}$, then transfected with the EGFP vector or with shcrt1/2 or sh-control. Forty-eight hours later, cells were lysed and Western blot performed on the extracts $(\boldsymbol{A})$. CRT levels were quantified relative to actin levels $(\boldsymbol{B})$. Motoneurons were electroporated with the EGFP vector in combination with empty vector (e.v.), shcrt1/2, or sh-control and immunostained for (RT $48 \mathrm{~h}$ later (C). Immunostaining was quantified (D). Downregulation of CRT leads to motoneuron death $(\boldsymbol{E}, \boldsymbol{F})$. Motoneuron survival was assessed 1 and $2 \mathrm{~d}$ after electroporation with the EGFP vector in combination with e.V., shcrt1/2, or sh-control. All conditions were expressed relative to EGFP + e.v. condition (E). WT and (RT heterozygous ( $\left(\mathrm{Crt}^{+/-}\right)$Motoneurons were cultured and cell counting performed 1 and $2 \mathrm{~d}$ after seeding $(\boldsymbol{F})$. The killing effect of CRT downregulation is dependent on Fas activation $(\boldsymbol{G}, \boldsymbol{H})$. WT motoneurons were

( $3 \mathrm{~h})$, embryos were kept at $4^{\circ} \mathrm{C}$ in Hibernate E medium (Invitrogen).

Mice deficient for CRT (calreticulin ${ }^{+/-}$, C57BL/6 × CD1 background) were kindly provided by Professor M. Michalak (University of Alberta at Edmonton). The $\mathrm{crt}^{+/-}$line was maintained as hemizygotes by crossing transgenic males $\mathrm{crt}^{+/-}$with $\mathrm{crt}^{+/-}$females, the homozygous deletion being embryonic lethal (Mesaeli et al., 1999). Offspring were genotyped by PCR for the NEO cassette using the following primers: sense: 5'-TCGTGCTTTACGGTATCG CCGCTCCCGATT-3', antisense: 5'-CGCGGA TCCACCTCCCATGACAGCCATTTA-3'.

Neuron cultures. Motoneuron cultures were prepared from E12.5 mice embryos as described previously (Raoul et al., 2002). Briefly, cells were dissociated mechanically after trypsin treatment of the dissected spinal cords. The largest cells were isolated using iodixanol density gradient purification. After a final BSA cushion, motoneurons were plated onto poly-ornithinelaminin-coated wells in supplemented Neurobasal (Invitrogen) medium in the presence of a mixture of neurotrophic factors (NTFs; $1 \mathrm{ng} / \mathrm{ml}$ BDNF, $100 \mathrm{pg} / \mathrm{ml}$ GDNF, and $10 \mathrm{ng} / \mathrm{ml} \mathrm{CNTF),}$ completed with $2 \%$ horse serum, B27 supplement (Invitrogen), $0.05 \mathrm{~mm}$ L-glutamine, $25 \mu \mathrm{M}$ L-glutamate, and $25 \mu \mathrm{M} \beta$-mercaptoethanol.

Hippocampal and cortical neurons were, respectively, prepared from E17.5 and E15.5 embryos from transgenic SOD ${ }^{\mathrm{G} 93 \mathrm{~A}}$ and control mice. Neurons were dissociated mechanically after trypsin treatment and plated onto polyornithine-laminin-coated wells in Neurobasal complemented with $1 \mathrm{~mm}$ glutamine and $2 \%$ B27 (Invitrogen).

For immunocytochemistry experiments, motoneurons in culture were generally treated $24 \mathrm{~h}$ after seeding and fixed 16-24 h after. For survival assays, motoneurons were counted $48 \mathrm{~h}$ after treatment. Wherever indicated, motoneurons were electroporated before plating with DNA plasmids. Briefly, cell pellets, obtained after the last centrifugation on a BSA cushion, were resuspended in an electroporation buffer containing (in $\mathrm{mM}$ ): $125 \mathrm{NaCl}, 5$ KCL, $1.5 \mathrm{MgCl}_{2}$, 10 glucose, and 20 HEPES; $\mathrm{pH}$ 7.4, at a density of 50,000 cells for $100 \mu \mathrm{l}$ and 8 $\mu \mathrm{g}$ of plasmid pCCL-Ubc GFP (Langou et al., 2010 ) with the same molar amount of the plasmid of interest added. After 15 min of incubation, motoneurons were transferred to a $4 \mathrm{~mm}$ cuvette (Eurogentec) and electroporated using a square electroporator (BTX) (three pulses of $5 \mathrm{~ms}$ at $200 \mathrm{~V}$ with intervals of $1 \mathrm{~s}$ ). To evaluate motoneuron survival, we used the following reagents: soluble Fas ligand (sFasL) and enhancer

electroporated as in $(\boldsymbol{E})$. Motoneurons were treated $24 \mathrm{~h}$ later with Fas- $\mathrm{Fc}(1 \mu \mathrm{g} / \mathrm{ml})$ and survival assessed $48 \mathrm{~h}$ later (G). WT motoneurons were electroporated as in $(\boldsymbol{E})$, treated or not $12 \mathrm{~h}$ later with DETANONOate, and immunostained for Fas ligand $24 \mathrm{~h}$ later. FasL expression was quantified in EGFP-positive cells and expressed relative to EGFP alone condition $(\boldsymbol{H})$. Data are means $\pm S D$ of three independent experiments: ${ }^{*} p<$ $0.05,{ }^{* *} p<0.01$, and ${ }^{* * *} p<0.001$. 
antibodies, Fas-Fc, DETANONOate, L-NAME and D-NAME, purchased from Alexis Biochemical. Thapsigargin was purchased from Calbiochem, and tunicamycin and caffeine were from Sigma-Aldrich. Salubrinal and 1,2bis(2-aminophenoxy)ethane- $N, N, N^{\prime}, N^{\prime}$-tetraacetic acid tetrakis(acetoxymethyl) ester (BAPTA/AM) were from Alexis Corporation and z-AlaThr-Ala-Asp(OME)-fmk(z-ATAD-fmk) was purchased from MBL International.

NSC34 cells (Cashman et al., 1992) were maintained in DMEM (Invitrogen) supplemented with $10 \%$ fetal bovine serum. The transfection of NSC 34 cells was performed with Lipofectamine 2000 (Invitrogen), the ratio of ADN/lipofectamine was $1 \mu \mathrm{g} / 2.5 \mu \mathrm{l}$ Lipofectamine.

Expression vectors. An expression vector coding for CRT was PCR amplified from pCMV-sport6.1 (Open Biosystem) to introduce FLAG/HA tags and cloned into the pcDNA3.1 vector with the following primers: 5'-ATGTACCCATACGATGTTCCAGATTACGCTATGCTCCTTTCG GTGCCGCTCC-3' (forward) and 5'-TTACTTATCGTCGTCATCCTT GTAATCCAACAGCTCATCCTTGGCTTGG-3' (reverse). For co-electroporation and cotransfection, we used a pUbc-enhanced green fluorescent protein (EGFP) (Langou et al., 2010), together with shRNA against CRT (sh1-CRT and sh-2-CRT) in plKO.1 vectors under the human U6 promoter, provided by Sigma-Aldrich). The shRNA control was also from Sigma and targets a human gene (SPOCK) coding for osteonectin that does not cross-react with the mouse gene.

Immunocytochemistry. Cells were cultured at a density of 3000 cells per well then fixed at indicated times with $4 \%$ paraformaldehyde (PFA) for $20 \mathrm{~min}$ at $4^{\circ} \mathrm{C}$. Cells were washed three times with PBS and blocked in PBS (4\% BSA, 4\% heat-inactivated goat serum, and $0.1 \%$ Triton X-100) for $1 \mathrm{~h}$ and incubated at $4^{\circ} \mathrm{C}$ overnight with one of the following primary antibodies: rabbit anti-CRT 1/500 (SPA 600; Stressgen), rabbit anti-CRT 1/1000 (PA3 900; ABR), mouse anti-protein disulfide isomerase (PDI) 1/250 (SPA 891; Stressgen), mouse anti- nonphosphorylated neurofilament $\mathrm{H}$ (SMI32) 1/500 (Covance), rabbit anti-GADD 153 (F-168): sc-575 (CHOP) 1/150 (Santa Cruz Biotechnology), rabbit anti-PhosphoeIF2 $\alpha$ (Ser51) $1 / 200$ (Cell Signaling Technology), and rabbit anti-EGFP 1/1000 (TP401; Torrey Pines Biolabs).

Cells were washed three times with PBS, then incubated with the appropriate secondary antibody (Invitrogen), washed three times with PBS, stained with DAPI to visualize nuclei 1/10,000 (Sigma-Aldrich), and mounted in Mowiol (Sigma-Aldrich) solution. Cells were observed under a Leica DM IRB inverted fluorescence microscope and images captured with a KAPPA camera. For immunoquantification experiments, cell images were taken with a confocal Olympus BX50WI laser scanning microscope using a $40 \times$ objective, and fluorescence was analyzed using either ImageJ or MetaMorph software.

Immunohistochemistry. Mice were anesthetized then perfused transcardially with PBS followed by PFA $4 \%$ in PBS and the spinal cords were dissected out. After $5 \mathrm{~h}$ of incubation in PFA 4\%, spinal cords were incubated in 25\% sucrose in PBS overnight, then embedded in Optimal Cutting Temperature compound (CML). The $18-\mu \mathrm{m}$-thick cryosections were collected onto super plus frost slides (CML), washed with PBS, and incubated with PBS (4\% BSA, 4\% heat-inactivated goat serum, and $0.1 \%$ Triton X-100) for 1-2 h. Sections were then incubated with the appropriate primary antibodies overnight: rabbit anti-CRT 1/200 (PA3-900; ABR), chicken anti-CRT 1/400 (ab14234; Abcam), mouse anti-NeuN 1/600 (clone A60; Millipore), and rabbit monoclonal anti-BiP 1/150 (Cell Signaling Technology). Spinal cord sections were washed three times with PBS, incubated with the appropriate secondary antibody, washed three times with PBS, and mounted in Mowiol mounting medium. Motoneuron pictures were taken with an Apotome Axio Imager Z2 microscope using a $60 \times$ objective; immunoquantification was performed using ImageJ software.

Western blot. Western blots were done on cell lysates from cultured motoneurons $(30,000$ cells $=5 \mu \mathrm{g})$ or NSC34 cells $(300,000$ cells $=30$ $\mu \mathrm{g})$ harvested, respectively, at $48 \mathrm{~h}$ ( $24 \mathrm{~h}$ after treatment) or $48 \mathrm{~h}$ after transfection as well as on lysates from lumbar spinal cord dissected from WT or SOD $1^{\text {G93A }}$ mice from 30 to $110 \mathrm{~d}$ and SOD $1^{\text {WT }}$ or SOD $1^{\text {G85R }}$ mice at $350 \mathrm{~d}$. Samples were lysed in a lysis buffer containing the following (in mu): 50 Tris- $\mathrm{HCl}, \mathrm{pH} 7.5,150 \mathrm{NaCl}, 2$ EDTA, 2 EGTA, and 1\% SDS) supplemented with a protease inhibitor mixture (Roche Molecular

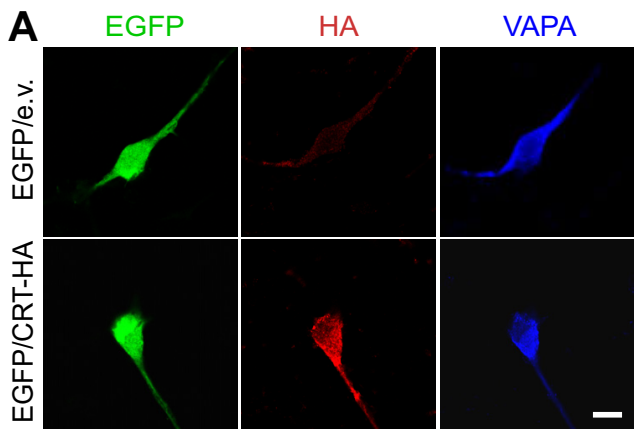

\section{B a wildtype 口SOD1G93A}

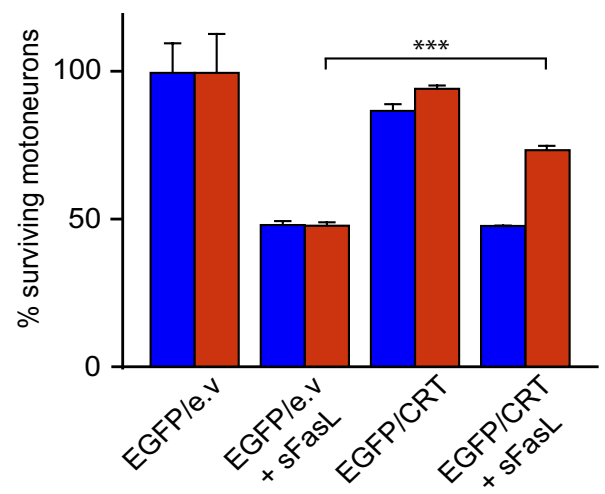

Figure 3. CRT overexpression prevents FasL/NO-induced death of SOD1 ${ }^{\mathrm{G} 93 \mathrm{~A}}$ motoneurons $(\boldsymbol{A}, \boldsymbol{B})$. WT or SOD1 ${ }^{\mathrm{G} 93 \mathrm{~A}}$ motoneurons were electroporated with EGFP/e.v. or EGFP/ CRT-HA vectors and were immunostained $24 \mathrm{~h}$ later for anti-HA to detect CRT and anti-VAPA to stain the ER $(\boldsymbol{A})$. Scale bar, $20 \mu \mathrm{m}$. Twenty four hours after electroporation with the same vectors as in $(\boldsymbol{A})$, motoneurons were treated or not with sFasL $(100 \mathrm{ng} / \mathrm{ml})$. Cell survival (EGFP-positive cells) was assessed $48 \mathrm{~h}$ later, and expressed relative to WT $(\boldsymbol{B})$. Data are from three independent experiments \pm SD: ${ }^{* * *} p<0.001$.

Biochemical). Protein concentration was determined using the BCA kit (Pierce). Protein samples were separated by SDS-PAGE and blotted to nitrocellulose membranes (Schleicher and Schuell, Whatman International). After blocking in 5\% milk, the following primary antibodies were used: rabbit anti-CRT 1/1000 (Stressgen) and mouse anti-actin (AC40, 1/20,000; Sigma). After incubation of the blots with horseradish peroxidase (HRP)-conjugated secondary antibodies, proteins were revealed on autoradiograms using the chemiluminescent HRP substrate (Millipore). Immunoblot images were quantified using the software ImageJ and normalized relative to actin levels.

Motoneuron retrograde labeling. WT or SOD $1{ }^{\mathrm{G} 93 \mathrm{~A}} 30$-d-old mice were anesthetized and injected in two regions of the tibialis or the soleus muscles with $10 \mu \mathrm{l}$ of tetramethyl-rhodamine dextran (3000 MW anionic, lysine-fixable, $20 \mathrm{mg} / \mathrm{ml}$ in $\mathrm{H}_{2} \mathrm{O}$ ). One week later, mice were anesthetized, and then perfused with PBS followed by PFA 4\% in PBS and bilateral muscles (soleus and tibialis) as well as spinal cords were dissected. Then $30-\mu \mathrm{m}$-thick sections of the muscles were cut and immediately examined by fluorescent microscopy to confirm proper injection sites, and $16-\mu \mathrm{m}$-thick cryosections were collected and immunostained for CRT/NeuN or P-eiF $2 \alpha / \mathrm{NeuN}$.

CRT, P-eiF2 $\alpha$, and NeuN immunofluorescence in Alexa-positive neurons was quantified using ImageJ software.

Calcium imaging. To monitor quantitative changes of $\left[\mathrm{Ca}^{2+}\right]_{\mathrm{i}}$ in motoneurons we used a Fura-Red acetoxymethyl ester (AM) dye (Invitrogen) that allows effective ratiometric fluorescence measurement. For dye loading, coverslips, on which motoneurons were cultured for $24 \mathrm{~h}$ and treated or not with sFasL $(100 \mathrm{ng} / \mathrm{ml})$ for $3 \mathrm{~h}$, were rinsed with an external solution containing (in $\mathrm{mm}$ ): $150 \mathrm{NaCl}, 2 \mathrm{KCl}, 2 \mathrm{MgCl}_{2}, 2 \mathrm{CaCl}_{2}, 10$

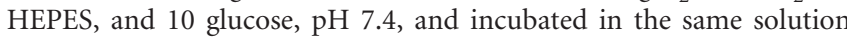



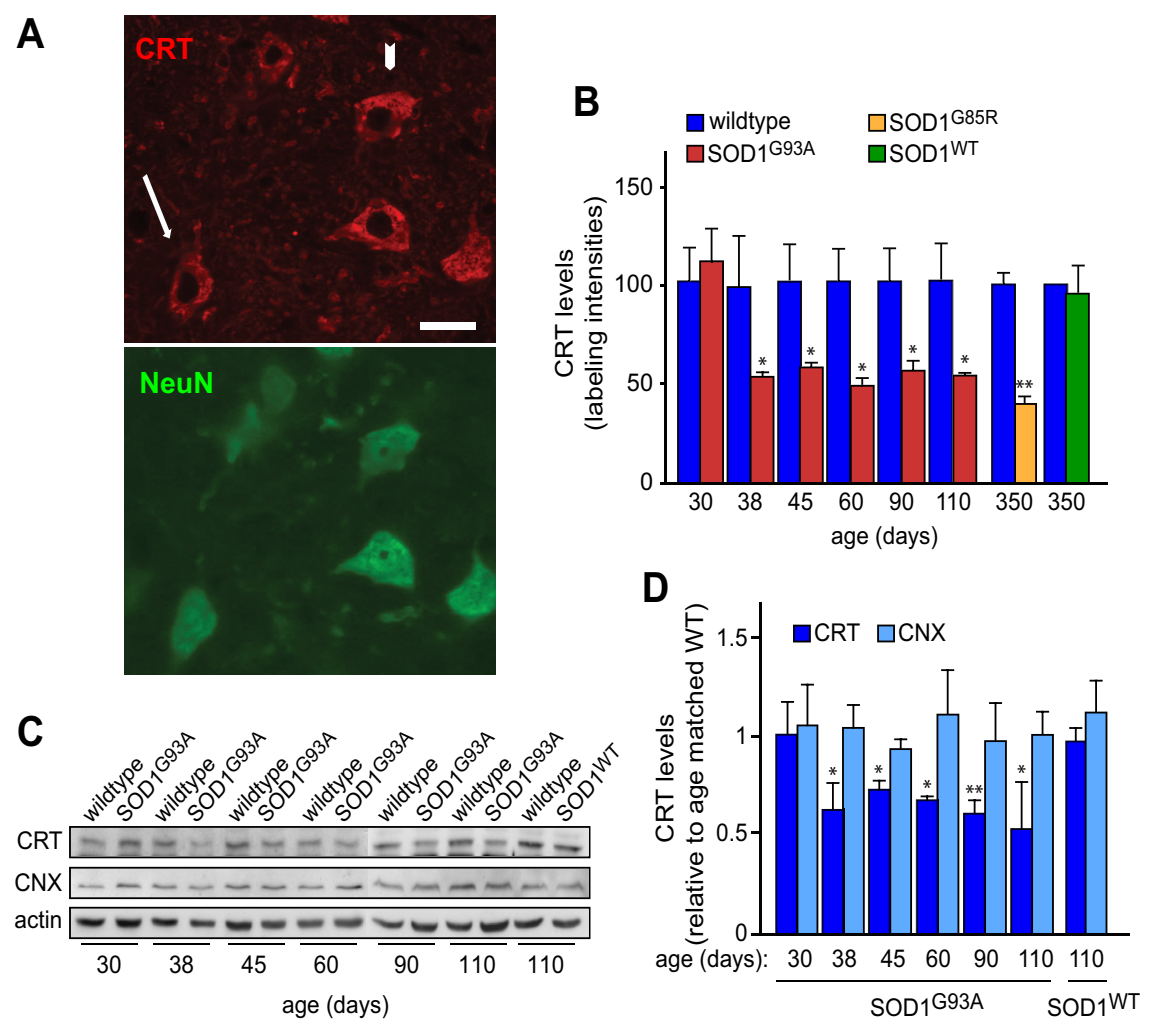

Figure 4. CRT expression is decreased in vivo in motoneurons in the SOD1 ${ }^{693 \mathrm{~A}}$ mice lumbar spinal cord starting at the asymptomatic stage $(\boldsymbol{A}-\boldsymbol{D})$. Immunostaining of CRT and NeuN was performed on spinal cord sections at the $L 3-\mathrm{L} 5$ levels in $30-$, 38-, and 45-d-old mice (asymptomatic); 60-d-old mice (presymptomatic); $90-\mathrm{d}$-old mice (onset of the disease); and 110-d-old mice (symptomatic). $A$, Enlargement of the ventral horn of a 38-d-old mSOD1 spinal cord. Scale bar, $50 \mu \mathrm{m}$. Long arrow $=$ low CRT expressor motoneuron, short arrow $=$ high CRT expressor motoneuron. Quantification of CRT and NeuN immunostaining was performed using NHI ImageJ software. Data are expressed as the CRT mean fluorescence in $\mathrm{SOD} 1^{\mathrm{G} 93 \mathrm{~A}}$ relative to CRT fluorescence in agematched WT mice $(\boldsymbol{B})$. Western blot for CRT and calnexin (CNX) from lumbar ventral spinal cord extracts was performed with mice of the same age as in $\boldsymbol{B}$. Quantification of the amounts of CRT and CNX using NHI ImageJ software, expressed as a ratio to the age-matched WT $(\boldsymbol{C}, \boldsymbol{D})$. Data in $\boldsymbol{B}-\boldsymbol{D}$ are from three independent experiments \pm SD for each age compared with the WT, ${ }^{*} \boldsymbol{p}<$ $0.05,{ }^{* *} p<0.01$.

containing $4 \mu \mathrm{M}$ Fura-Red AM for $30 \mathrm{~min}$ in the dark at $20^{\circ} \mathrm{C}$, the dye was washed off and the coverslips reincubated in the dark for a further $60 \mathrm{~min}$ at $20^{\circ} \mathrm{C}$ to allow de-esterification of the dye. After loading, coverslips were transferred to the stage of a Nikon Diaphot 300 microscope $(20 \times$ or $40 \times$ long distance lens). To selectively visualize $\mathrm{Ca}^{2+}$ in motoneurons we first focused on transmitted light and thereafter acquired fluorescent images of Fura-Red. Fura-Red was alternately excited at 440 (10) nm and 490 (10) nm using a xenon light source (Sutter Instruments), and emission collected at 660 (50) nm using a CCD camera (Hamamatsu). All filters were bandpass with bandwidths indicated in parentheses (Chroma Technology). Images were acquired at $5 \mathrm{~s}$ intervals and analyzed off-line with SimplePCI software (Hamamatsu). For $\left[\mathrm{Ca}^{2+}\right]_{\mathrm{i}}$ analysis we first drew regions of interest on motoneurons and then applied these regions of interest for analysis of Fura-Red images. $\left[\mathrm{Ca}^{2+}\right]_{i}$ values were presented as the $490 / 440 \mathrm{~nm}$ ratio. During experiments, neurons were continuously perfused with external solution. Fifteen seconds after beginning the experiment neurons were activated by a brief $(8 \mathrm{~s})$ application of the external solution containing $25 \mathrm{~mm} \mathrm{KCl}$ (replacing equimolar amount of $\mathrm{NaCl}$ in the external solution), applied via a fast perfusion system. After $\mathrm{KCl}$ application, the cells were perfused with the $\mathrm{KCl}$-free solution for an additional $3 \mathrm{~min}$ to let them recover.

Sciatic nerve crush. Twenty-five-day-old BL6/SJL mice were anesthetized and nerve crush was performed as described previously (Magill et al., 2007). Briefly, skin was incised $1 \mathrm{~mm}$ posterior and parallel to the femur and the sciatic nerve was pulled out of the biceps femoris. The sciatic nerve was then crushed for $30 \mathrm{~s}$ with a No. 5 jeweler's forceps, 5 $\mathrm{mm}$ proximal to its trifurcation. Closure of the muscle and skin was achieved by suturing with a $6-0$ nylon thread. Animals were anesthetized and perfused $2 \mathrm{~d}$ later; $20 \mu \mathrm{m}$ spinal cord cryosections were performed on the lumbar L3-L5 segments and immunostained for BiP and CRT.

CRT and BiP immunofluorescence was quantified using ImageJ software.

Statistical methods. For survival and immunoquantification experiments, differences were evaluated for their statistical significance by two-tailed, unpaired Student's $t$ test. Values were expressed as percents $\pm S D$.

For calcium imaging, statistical analysis was performed using the GraphPad Instat software (GraphPad Software). Tests used were based on either parametric (unpaired $t$ test, Welch corrected) or nonparametric (Mann-Whitney) data depending on the normality test. Significance was accepted as the level of $p<0.05$ ${ }^{\star} p<0.05,{ }^{* *} p<0.01$, and $\left.{ }^{* *} p<0.001\right)$.

\section{Results}

Activation of the Fas/NO pathway in mSOD1 motoneurons leads to reductions in levels of CRT

We sought to identify molecular changes responsible for the increased sensitivity of ALS mutant motoneurons to death induced by Fas. In an earlier study (Duplan et al., 2010) we used 2D gel electrophoresis and peptide sequencing to identify proteins whose levels change when primary cultures of SOD $1{ }^{\text {G85R }}$ motoneurons are exposed for $24 \mathrm{~h}$ to the $\mathrm{NO}$ donor DETANONOate, which is known to activate the Fas pathway in motoneurons and to kill half of them after $48 \mathrm{~h}$. One such protein (reported in supplemental Table 1 available at www.jneurosci.org as supplemental material) in (Duplan et al., 2010) but not further studied in that paper, was CRT. Spot volumes for CRT expressed as a percentage of the signal for untreated WT cultures did not differ significantly between untreated WT $(100 \pm 18$; mean $\pm \mathrm{SD}, n=4)$ and untreated SOD $1{ }^{\text {G85R }}$ neurons $(95 \pm 18)$. In contrast, exposure to NO led to a twofold reduction in CRT levels in SOD ${ }^{\text {G85R }}$ (48 \pm $17)$ but not in WT $(132 \pm 20)$ motoneurons. To ascertain whether NO was acting as expected through activation of the Fas/NO feedback loop, we exposed embryonic motoneurons to sFasL for $24 \mathrm{~h}$ and subsequently performed quantitative immunocytochemistry for CRT. Like NO, sFasL triggered a twofold decrease in CRT levels in SOD $1^{\mathrm{G} 93 \mathrm{~A}}$ motoneurons but not in controls (Fig. $1 A, B$ ). This result was confirmed by Western blot analysis (Fig. 1C,D). Moreover, the decrease in CRT induced by sFasL was blocked by treatment with an inhibitor of NO synthase (NOS; data not shown). These results demonstrate that activation of the Fas/NO cell death pathway in ALS model motoneurons triggers a reduction in levels of CRT.

We next asked whether CRT reduction was specific to $\mathrm{mSOD} 1$ models and the Fas/NO pathway. Similar reductions were observed using motoneurons expressing either of two different ALS-linked SOD1 mutations (SOD1 ${ }^{\mathrm{G} 93 \mathrm{~A}}$ or SOD $1^{\mathrm{G} 85 \mathrm{R}}$ ) but not nontransgenic (WT) motoneurons or those expressing the WT form of human SOD1 (SOD1 ${ }^{\mathrm{WT}}$ ) (Fig. $1 \mathrm{E}$ ). Strikingly, the reduction was specific to motoneurons: cultures of cortical or hip- 
pocampal neurons from SOD ${ }^{\text {G93A }}$ mice did not show any reduction in CRT expression when treated with NO (Fig. $1 F$ ). Moreover, changes were specific to the Fas pathway. LIGHT (lymphotoxin-related inducible ligand that competes for glycoprotein D binding to herpes virus entry mediator on T cells) is a member of the TNF family that induces motoneuron death through a mechanism distinct from that of Fas (Aebischer et al., 2011); it did not modify CRT expression in SOD1 G93A neurons (Fig. $1 B$ ). Similarly, death induced by absence of trophic factors was not accompanied by reductions in CRT (data not shown). Last, levels of another ER-resident protein, PDI, were increased rather than decreased in sFasL-treated SOD $1^{\text {G93A }}$ motoneurons (Fig. $1 G$ ). Therefore, one selective effect of activation of the Fas/NO pathway, to which mSOD1 motoneurons show an exacerbated response, is downregulation of the ER chaperone CRT.

\section{Reduced levels of CRT are sufficient to trigger motoneuron} death through activation of the Fas/NO pathway

It remained possible that reduced CRT levels were a secondary effect of Fas activation unrelated to the death pathway. We therefore asked whether reduced levels of CRT expression are alone sufficient to induce motoneuron death.

As a first approach, we knocked down CRT expression using RNA interference. We evaluated two shRNAs to mouse CRT (sh1 and sh2) as well as a control, a shRNA to human osteonectin (sh-control). Motoneuron-like NSC34 cells were cotransfected with each shRNA together with an EGFP- expressing plasmid to identify transduced cells. Western blot analysis revealed a 25$50 \%$ reduction in expression levels using the two shRNAs, whereas no inhibition was observed with the control shRNA (Fig. $2 A, B)$. Accordingly, immunolabeling intensity for CRT was diminished by $\sim 40 \%$ in motoneurons electroporated with sh1CRT but not with sh-control (Fig. 2C,D).

To determine whether reductions in CRT affect survival, motoneurons were electroporated with each shRNA together with the EGFP plasmid and seeded in medium containing NTFs. At 24 and $48 \mathrm{~h}$ of culture the number of EGFP-positive motoneurons present was expressed relative to values at the same time point for motoneurons electroporated with the EGFP plasmid alone. Treatment with either sh1-CRT or sh2-CRT led to a $\sim 50 \%$ decrease in survival, concomitant with the degree of reduction in CRT levels (Fig. 2E). Treatment with sh-control did not affect survival at either time point. However, it remained possible that the altered survival reflected off-target effects of the shRNAs to CRT. We therefore isolated motoneurons from E12.5 embryos of heterozygous $\mathrm{crt}^{+/-}$mice and WT littermates (Mesaeli et al., 1999). Even in the presence of NTFs, $\mathrm{crt}^{+/-}$motoneurons showed a $20 \%$ decrease in survival compared with WT after $24 \mathrm{~h}$, and a $40 \%$ decrease after 48 h (Fig. 2 F). Therefore, like Fas activation, reduction of CRT levels can trigger motoneuron death even in the presence of an optimal mixture of survival factors.

As CRT reduction is downstream of Fas/NO activation, it was possible that motoneuron death in these conditions occurred through a different mechanism. However, since the Fas/NO pathway is a self-amplifying loop, it was also possible that low CRT acted through activation of Fas. To distinguish between these possibilities, CRT was silenced in motoneurons and cells were treated or not with Fas-Fc, a soluble dominant-negative form of Fas that blocks activation of Fas by FasL. Strikingly, Fas-Fc prevented most of the death induced by CRT knockdown after $48 \mathrm{~h}$ (Fig. 2G). Moreover, we found that reductions in CRT led to an increase in FasL immunoreactivity in transduced mo-
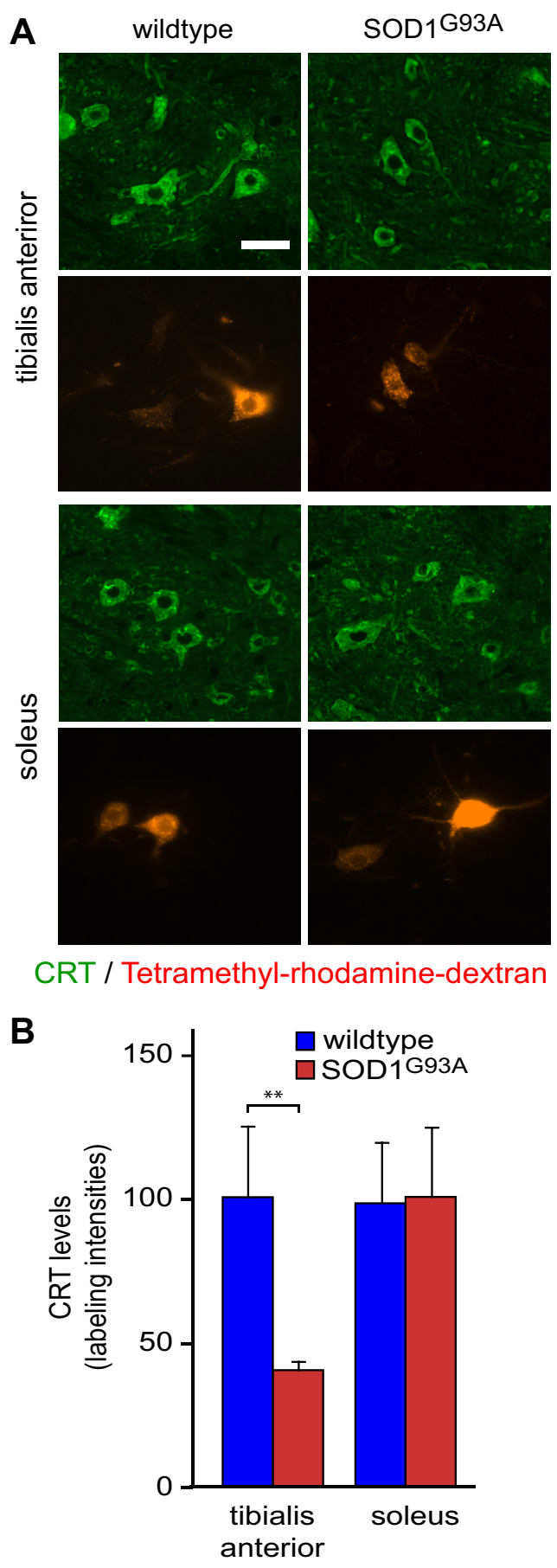

Figure 5. Decrease in CRT expression occurs only in vulnerable motoneurons. $A$, Immunostaining of CRT was performed on lumbar spinal cord sections $7 \mathrm{~d}$ after injection of tetramethylrhodamine-dextran in the tibialis (vulnerable motoneurons) or in the soleus (resistant motoneurons) muscle. Scale bar, $50 \mu \mathrm{m}$. $\boldsymbol{B}$, Immunofluorescence of CRT was quantified using $\mathrm{NHI}$ ImageJ software in tetramethyl-rhodamine-dextran-labeled motoneurons in WT or SOD1 ${ }^{\text {G93A }}$ mice at $38 \mathrm{~d}$, and data expressed relative to the WT. Data in $\boldsymbol{B}$ were from three independent experiments \pm SD for each age compared with the WT. ${ }^{* *} p<0.01$.

toneurons (Fig. $2 \mathrm{H}$ ). These data point to a key role for decreased CRT expression in the Fas/NO amplification loop, the diminution of CRT expression leading to upregulation of FasL which in turn activates Fas, leading to a further decrease in CRT expression.

These findings suggested that the reduction in CRT might be essential for activity of the Fas/NO loop to reach levels sufficient 


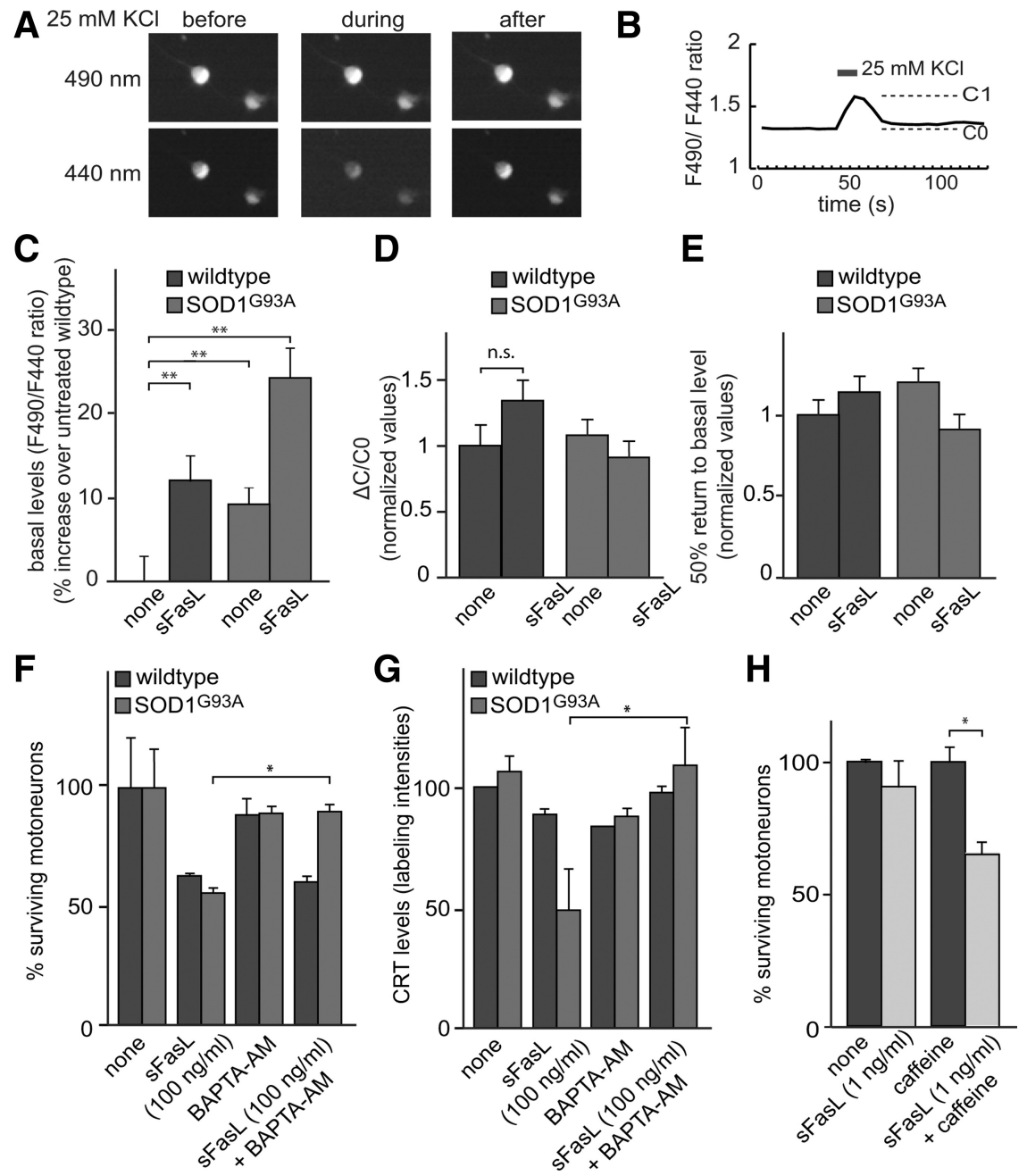

Figure 6. Calcium signaling is involved in $\mathrm{SOD} 1{ }^{\mathrm{G} 93 \mathrm{~A}}$ motoneuron death triggered through Fas. Ratiometric $\left[\mathrm{Ca}^{2+}\right]_{\mathrm{i}}$ measurement in motoneurons. Representative motoneurons loaded with Fura-Red dye before, during, and after $25 \mathrm{~mm} \mathrm{KCl} \mathrm{stimulation.} \mathrm{Top}$ row, Represents the calcium-insensitive, $490 \mathrm{~nm}$ excitation wavelength. Bottom row, Represents the calcium-sensitive, $440 \mathrm{~nm}$ excitation wavelength $(\boldsymbol{A})$. Fura-Red fluorescence change when excited using 440 and $490 \mathrm{~nm}$ filters in response to $\mathrm{KCl}$ application is illustrated as a ratio of fluorescence intensities $(\boldsymbol{B})$. Basal level of $\left[\mathrm{Ca}^{2+}\right]_{i}(\boldsymbol{C})$, amplitudes of neuronal response to application of $25 \mathrm{~mm} \mathrm{KCl}(\boldsymbol{D})$, and 50\% recovery time after $\mathrm{KCl}$ application $(\boldsymbol{E})$ were measured in different motoneurons, WT versus SOD1 ${ }^{\mathrm{G9} A}$ treated or not with sFasL. Data are from four experiments with $20-30$ neurons analyzed per experiment. Values \pm SEM; ${ }^{* *} p<$ 0.01. Chelating intracellular calcium with BAPTA-AM prevents sFasL-induced death and CRT decrease of SOD $1^{\text {G93A }}$ motoneurons $(\boldsymbol{F}, \boldsymbol{G})$. WT or SOD ${ }^{\mathrm{G} 93 \mathrm{~A}}$ motoneurons were treated with sFasL $(100 \mathrm{ng} / \mathrm{ml})$ in combination or not with BAPTA-AM $(5 \mu \mathrm{g} / \mathrm{ml})$ and motoneuron survival $(\boldsymbol{F})$, and $(R T$ levels $(\boldsymbol{G})$ were assessed 48 and $24 \mathrm{~h}$ after, respectively. Increasing cytoplasmic calcium with caffeine treatment potentiates death triggered through Fas activation in WT motoneurons $(\boldsymbol{H})$. WT motoneurons were cultured for $24 \mathrm{~h}$, then treated with a sublethal dose of sFasL $(1 \mathrm{ng} / \mathrm{ml})$ and/or caffeine $(10 \mu \mathrm{g} / \mathrm{ml})$ and cell survival was evaluated $48 \mathrm{~h}$ after treatment. Data are means \pm SD of three independent experiments: ${ }^{*} p<0.05,{ }^{* *} p<0.01$. n.S., not significant.

for cell killing. To test this directly, we studied the response to Fas activation of motoneurons in which CRT was kept artificially high. SOD $1^{\text {G93A }}$ and WT motoneurons were electroporated with a plasmid-encoding mouse CRT tagged with hemagglutinin (CRT-HA) or an empty vector control, together with an EGFP plasmid to identify electroporated motoneurons. Expression of CRT-HA was confirmed by motoneuron immunostaining (Fig. $3 A$ ). Twenty-four hours after seeding, to allow time for CRT expression, cells were treated or not with sFasL (or NO; data not shown) and survival was assessed $48 \mathrm{~h}$ later by counting EGFPpositive motoneurons. Overexpression of CRT prevented the death of $\sim 60 \%$ of the SOD $1^{\mathrm{G} 93 \mathrm{~A}}$ motoneurons that were lost following sFasL treatment of controls (Fig. 3B). Unexpectedly, however, raising CRT had no effect on the FasL-induced death of WT motoneurons (Fig. 3B). Two conclusions could be drawn from these findings. First, the reduction in CRT is an integral part of the Fas/NO death pathway and is both necessary and sufficient to trigger death of ALS-mutant motoneurons through this feedback loop. Second, the cell death mechanism downstream of Fas in SOD1 ${ }^{\mathrm{G} 93 \mathrm{~A}}$ motoneurons is distinct from, not just a simple amplification of, the death pathway through which Fas kills WT motoneurons. This suggested that cellular events caused by low CRT may be specific to ALS.

\section{CRT expression is reduced in mSOD1 motoneurons in vivo before symptom onset}

To strengthen the links to the disease, it was essential to confirm that CRT expression was also modulated in MSOD1 mice in vivo. CRT levels were first assessed by double-staining of lumbar spinal cord sections for CRT and NeuN (labels all $\alpha$-motoneurons) (Fig. $4 A$; data not shown), and CRT levels were calculated as ratios of CRT to NeuN fluorescence intensities. In SOD $1^{\text {G93A }}$ mice, CRT levels at $30 \mathrm{~d}$ were identical to those in nontransgenic controls (WT). Subsequently, starting at $38 \mathrm{~d}$, before overt symptoms can be detected, there was a twofold diminution in CRT expression that persisted to symptomatic stages $(110 \mathrm{~d})$ (Fig. $4 \mathrm{~B}$ ). Similar results were obtained using SOD1 ${ }^{\mathrm{G} 85 \mathrm{R}}$ mice at symptomatic stages ( $350 \mathrm{~d}$ ), whereas no diminution was observed in SOD $1^{\mathrm{WT}}$ mice (Fig. 4B). An overall reduction in CRT levels was also detected by Western blot analysis of ventral spinal cord (Fig. 4C,D). These observations were specific to motoneurons and CRT: levels in dorsal spinal interneurons at lumbar levels remained high in mSOD1 mice (data not shown), and levels of calnexin, another ER resident chaperone protein, did not change in motoneurons (Fig. 4D). Thus, as in Fastreated motoneurons in vitro, CRT downregulation in vivo is a selective response of motoneurons to expression of ALS-linked SOD1 mutants.

\section{Reductions in CRT levels in vivo are restricted to} ALS-vulnerable motoneurons

The fact that there was only partial loss of CRT in ALS motoneurons could reflect an overall 50\% decrease in expression levels or could indicate a diversity of the response in different motoneuron populations. We compared different spinal levels and found that the diminution in CRT expression was not observed in thoracic motoneurons of the SOD $1^{\mathrm{G} 93 \mathrm{~A}}$ spinal cord (data not shown). The CRT change therefore seemed potentially limited to limb-innervating motoneurons, which are known to be more vulnerable to ALS.

Even at lumbar levels, however, the loss of CRT was not complete, suggesting that different motor pools might respond in 
different ways. Within the lumbar spinal cord, motoneurons innervating fast fatigable muscles such as the tibialis anterior have been shown to be more vulnerable in SOD $1^{\text {G93A }}$ mice than those innervating predominantly slow muscles such as the soleus (Frey et al., 2000; Pun et al., 2006). We therefore asked whether the CRT decrease was restricted to vulnerable motoneurons. Vulnerable and resistant motoneurons were retrogradely labeled by injecting 30-d-old WT or SOD ${ }^{\mathrm{G} 93 \mathrm{~A}}$ mice with tetramethyl-rhodamine-dextran into the tibialis anterior and soleus muscles, respectively. Eight days later, at $38 \mathrm{~d}$, sections of spinal cord were costained for CRT and NeuN and levels of CRT relative to NeuN were measured only in retrogradely labeled neurons (Fig. $5 A, B$ ). Soleus motoneurons showed CRT levels that were indistinguishable between nontransgenic and SOD1 G93A mice (Fig. 5B). In contrast, levels of CRT in vulnerable tibialis anterior motoneurons were reduced by $60 \%$ (Fig. $5 B$ ). As a positive control, we checked (data not shown) that P-eIF2 $\alpha$ expression was increased specifically in vulnerable motoneurons (Saxena et al., 2009). There is therefore a close correlation between decreased CRT expression and vulnerability of motoneurons in SOD 1 G93A mice. Moreover, the reduction in CRT precedes the axonal die-back that is the first morphological sign of degeneration in the vulnerable populations.

\section{Defective calcium handling contributes} to vulnerability of SOD 1 G93A

motoneurons to Fas/NO-induced death We next considered how reductions in CRT might contribute to selective degeneration of motoneurons expressing mSOD1. One key function of CRT is to maintain calcium homeostasis (Verkhratsky, 2002). We therefore first determined whether calcium handling was modified in SOD1 G93A versus WT motoneurons treated or not with sFasL (100 ng/ml). Following treatment for $3 \mathrm{~h}$ with sFasL, cells were loaded with Fura-Red AM (see Materials and Methods) and fluorescence intensity ratios F490/F440 were monitored before, during, and after a brief ( $8 \mathrm{~s}$ ) pulse of 25 $\mathrm{mm} \mathrm{KCl}$ to estimate $\mathrm{Ca}_{\mathrm{i}}$ (Fig. $6 A, B$ ). We detected no significant difference between WT and SOD1 ${ }^{\text {G93A }}$ motoneurons in their response to the $\mathrm{KCl}$ stimulus (Fig. $6 \mathrm{D}$ ) or in the rate to return to basal levels (Fig. $6 E$ ) suggesting that the cells were in good health. Both WT and mutant motoneurons showed increases in the basal level of intracytoplasmic calcium following $3 \mathrm{~h}$ of treatment with sFasL. However, not only was the basal $\mathrm{Ca}_{\mathrm{i}}$ level higher in SOD $1^{\mathrm{G} 93 \mathrm{~A}}$ neurons but the increase in $\mathrm{Ca}_{\mathrm{i}}$ triggered by sFasL was twofold greater (Fig. $6 \mathrm{C}$ ). The reduction in CRT may therefore amplify the consequences of calcium homeostasis defects.
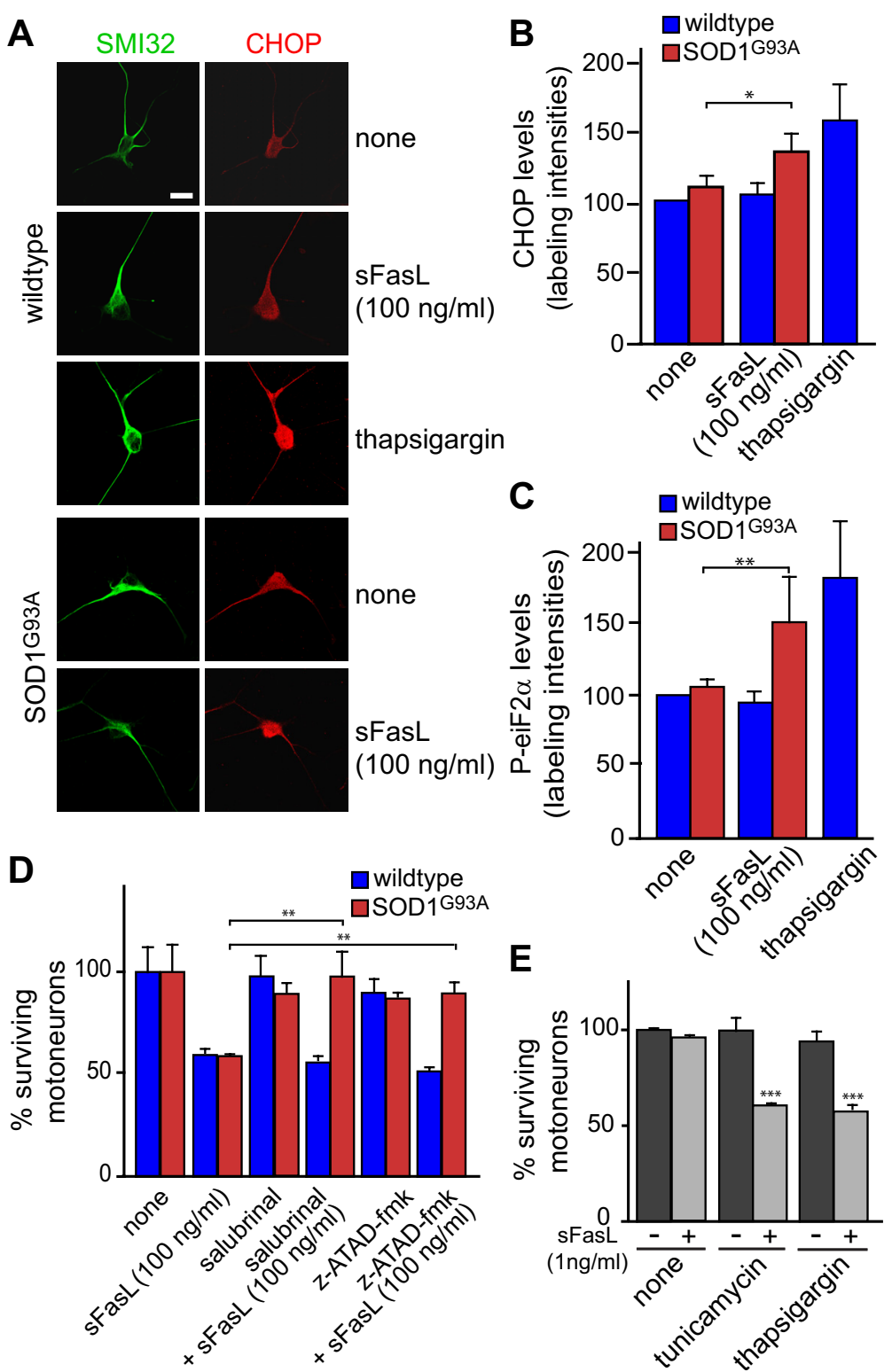

Figure 7. ER stress is involved in $\mathrm{SOD} 1{ }^{\mathrm{G} 93 \mathrm{~A}}$ motoneuron death triggered through Fas. ER stress markers $\mathrm{CHOP}$ and P-elF2 $\alpha$ are upregulated in SOD1 ${ }^{\mathrm{G} 93 \mathrm{~A}}$ motoneurons treated with SFasL $(A-C)$. WT or SOD1 ${ }^{\mathrm{G} 93 \mathrm{~A}}$ motoneurons were cultured for $24 \mathrm{~h}$, then treated with sFasL $(100 \mathrm{ng} / \mathrm{ml})$ or thapsigargin $(20 \mathrm{~nm}, 2 \mathrm{~h})$ and immunostained $24 \mathrm{~h}$ after for CHOP $(\boldsymbol{A}, \boldsymbol{B})$ or P-elF2 $\alpha(\boldsymbol{C})$ in combination with a motoneuronal marker, SMI32. Scale bar (in $A$ ), $20 \mu \mathrm{m}$. The mean intensity of fluorescence was quantified using MetaMorph software. Inhibiting ER stress prevents sFasL-induced death of SOD $1^{\text {G93A }}$ motoneurons (D). WT or SOD1 ${ }^{\text {G93A }}$ motoneurons were cultured for $24 \mathrm{~h}$ then treated for $24 \mathrm{~h}$ with sFasL ( $100 \mathrm{ng} / \mathrm{ml}$ ) and/or salubrinal (ER stress inhibitor, $5 \mu \mathrm{m})$ or Z-ATAD-fmk (caspase-12 inhibitor, $10 \mu \mathrm{m}$ ). Combined sublethal doses of $s$ Fas ligand ( $\mathrm{sFas} \mathrm{L}$ ) and ER stress inducers result in death of WT motoneurons $(\boldsymbol{E})$. WT motoneurons were cultured for $24 \mathrm{~h}$, then treated for $48 \mathrm{~h}$ with sublethal doses of sFasL $(1 \mathrm{ng} / \mathrm{ml})$ and/or of ER stress inducers tunicamycin $(0.05 \mu \mathrm{g} / \mathrm{ml})$ or thapsigargin $(0.1 \mathrm{~nm})$. Cell survival was measured and results for each condition expressed relative to the nontreatment condition. Data are means \pm SD of three independent experiments, expressed relative to untreated condition: ${ }^{*} p<\mathrm{p} 0.05,{ }^{* *} p<0.01$, and ${ }^{* * *} p<0.001$.

To determine whether the altered calcium homeostasis plays a functional role in motoneuron vulnerability, motoneurons were cultured with or without $5 \mu \mathrm{g} / \mathrm{ml}$ BAPTA-AM, a cytoplasmic calcium scavenger. BAPTA-AM did not affect the death of WT motoneurons treated with sFasL $(100 \mathrm{ng} / \mathrm{ml})$ but completely inhibited the death of (Fig. $6 F$ ) and the decrease in CRT (Fig. 6G) in SOD $1^{\text {G93A }}$ motoneurons in the same conditions. These results suggested that a suprathreshold increase in calcium might explain the decrease in CRT and the increased sensitivity of SOD $1^{\text {G93A }}$ motoneurons to Fas activation. We reasoned that if 
A

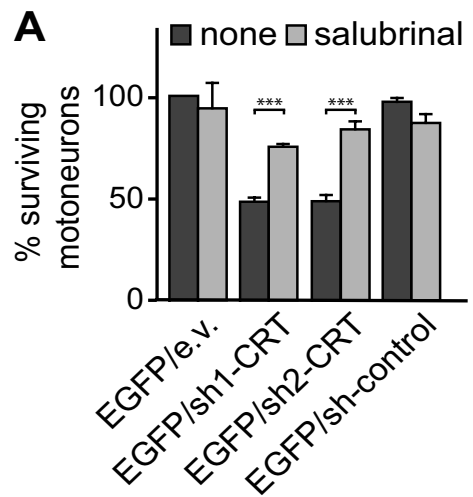

C

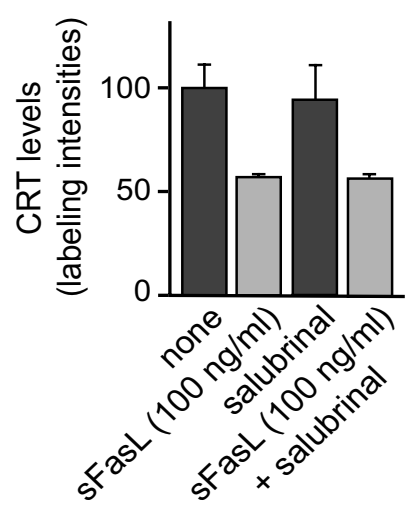

$\mathbf{E}$
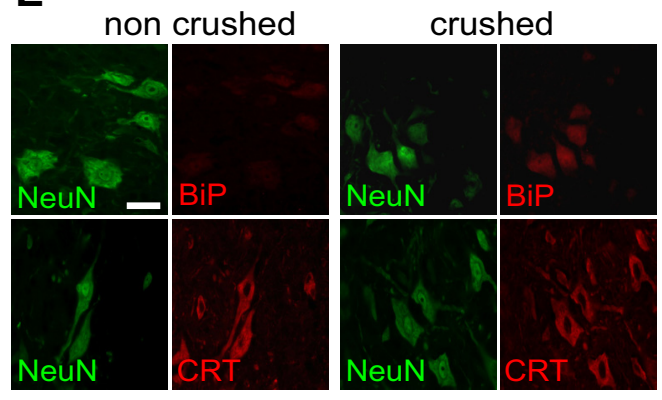

B

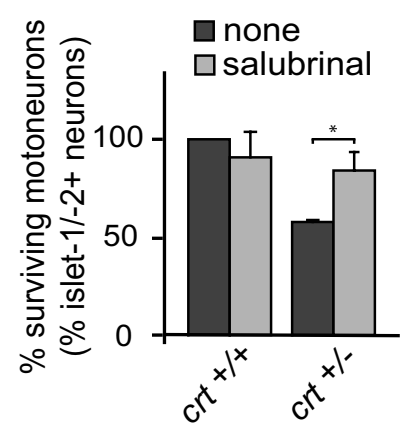

D

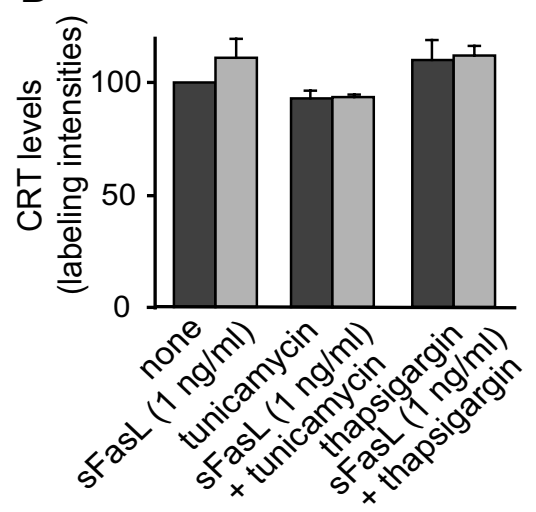

F $\quad$ anon crushed

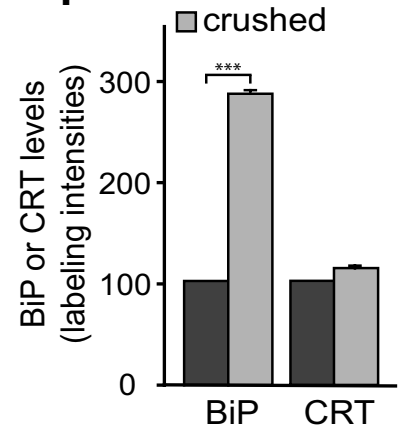

Figure 8. CRT decreased expression is upstream and independent of ER stress activation. Death of motoneurons induced by downregulation of $C R T$ is dependent on ER stress $(\boldsymbol{A}, \boldsymbol{B})$. Motoneurons were electroporated with EGFP in combination with empty or sh-crt $1 / 2$ or sh-control vectors and treated or not with salubrinal $(5 \mu \mathrm{M})$. Cell survival was assessed $48 \mathrm{~h}$ after $(A)$. WT and $\mathrm{rrt}^{+/-}$ motoneurons were treated with salubrinal $8 \mathrm{~h}$ after seeding and assayed for survival at $48 \mathrm{~h}(\boldsymbol{B})$. Blocking ER stress does not prevent decrease in CRT in SOD ${ }^{\mathrm{G} 93 \mathrm{~A}}(\boldsymbol{C})$. Motoneurons were treated $24 \mathrm{~h}$ after seeding with SFasL $(100 \mathrm{ng} / \mathrm{ml})$, in combination or not with salubrinal $(5 \mu \mathrm{M})$. CRT immunostaining was performed $24 \mathrm{~h}$ later. Induction of ER stress in WT motoneurons does not lead to decreased expression of CRT (D). WT motoneurons were treated at $24 \mathrm{~h}$ after seeding with sublethal doses of $\mathrm{sFasL}(1 \mathrm{ng} / \mathrm{ml})$, tunicamycin $(0.05 \mu \mathrm{g} / \mathrm{ml})$, or thapsigargin $(0.1 \mathrm{nM})$. CRT/SMl32 double-immunostaining was performed $24 \mathrm{~h}$ later and CRT expression was quantified relative to SMI32. Data are means \pm SD of three independent experiments. ER stress induced by nerve crush does not lead to $C R T$ decrease $(\boldsymbol{E}, \boldsymbol{F})$. CRT and BiP expression were visualized $(\boldsymbol{E})$ and quantified $(\boldsymbol{F})$ relative to NeuN in L3-L5 sections of spinal cords from WT mice at $30 \mathrm{~d}, 2 \mathrm{~d}$ after sciatic nerve crush was performed on one side. $C, \boldsymbol{D}, \boldsymbol{E}$, Immunostainings were quantified with NHI ImageJ software and expressed relative to untreated and/or WT. Scale bar, $50 \mu \mathrm{m}$. Data in $(\boldsymbol{F})$ are means \pm SD of three independent experiments: ${ }^{*} p<0.05,{ }^{* * *} p<0.001$.

this was correct, inducing calcium release from the ER should be sufficient to trigger the death of WT motoneurons exposed to a low dose of sFasL normally only sufficient to kill mutant neurons. WT motoneurons were treated with caffeine, which depletes ER calcium stocks, in the presence or not of sFasL $(1 \mathrm{ng} / \mathrm{ml})$. Induced calcium release from the ER indeed conferred enhanced sensitivity to Fas on WT motoneurons (Fig. $6 \mathrm{H}$ ). Our data suggest that although $\mathrm{Ca}_{\mathrm{i}}$ increases following multiple treatments, a threshold level is required to trigger death. This is reached in SOD1 ${ }^{\mathrm{G} 93 \mathrm{~A}}$ but not WT motoneurons exposed to Fas agonists and reflects a failure of WT motoneurons to release calcium from the ER to the same degree.

\section{ER stress contributes to enhanced vulnerability of mSOD1 motoneurons to Fas activation}

Impairment of CRT function in other cell types leads to less efficient protein folding (Molinari et al., 2004), and CRT-deficient fibroblasts activate PERK-dependent ER stress signaling pathways (Knee et al., 2003). We therefore tested the hypothesis that ER stress could, as in vulnerable motoneurons in vivo (Saxena et al., 2009), contribute to the increased susceptibility of mSOD1 motoneurons to Fas activation.

We first determined whether treatment of cultured motoneurons with sFasL leads to ER stress as revealed by two markers: p-eIF2 $\alpha$ (phosphorylated following PERK activation) and CHOP (transcribed following PERK activation). As a positive control, a short-time, high-level thapsigargin treatment of WT neurons induced strong increases in levels of both (Fig. $7 B, C)$. Levels of ER stress markers were equivalent in untreated WT and mSOD1 motor neurons. When WT motoneurons were treated for $16 \mathrm{~h}$ with sFasL at 100 $\mathrm{ng} / \mathrm{ml}$, a concentration sufficient to trigger their subsequent death, no increase in ER stress was detected (Fig. $7 A-C$ ). In contrast, exposure of SOD1 ${ }^{\mathrm{G} 93 \mathrm{~A}}$ motoneurons to the same concentration of sFasL clearly exacerbated ER stress (Fig. 7A-C). ER stress is therefore not a general response of motoneurons to Fas signaling but is activated selectively in mSOD1 motoneurons.

This suggested that the differential in the sensitivity of SOD $1^{\mathrm{G} 93 \mathrm{~A}}$ motoneurons to Fas/NO might reflect a functional contribution of ER stress. Accordingly salubrinal, which inhibits eIF2 $\alpha$ dephosphorylation and therefore ER stress responses, provided strong protection against SOD1 ${ }^{\mathrm{G} 93 \mathrm{~A}}$ motoneuron death induced by Fas, but did not affect survival of WT motoneurons in the same conditions (Fig. 7D). Similarly selective protection of SOD1 ${ }^{\mathrm{G} 93 \mathrm{~A}}$ neurons was provided by ATAD, an inhibitor of caspase-12 (implicated in ER stress) and by MDL, an inhibitor of calpains (which cleave caspase-12) (Fig. 7D; data not shown). Thus ER stress can account for a significant part of the exacerbated vulnerability of SOD $1^{\mathrm{G} 93 \mathrm{~A}}$ motoneurons to Fas activation.

These data suggested that the lower sensitivity of WT neurons to Fas/NO reflects their failure to activate ER stress. We therefore asked whether an ER stress inducer could mimic the effect of SOD1 ${ }^{\text {G93A }}$ expression on Fas vulnerability. We treated WT mo- 
toneurons with low-dose sFasL $(1 \mathrm{ng} / \mathrm{ml})$ in the presence or not of low levels of ER stress inducers tunicamycin or thapsigargin. These were added at concentrations that alone are insufficient to trigger death but capable of inducing ER stress (data not shown). Strikingly, induction of a mild ER stress in WT motoneurons renders them sensitive to a 100 -fold lower concentration of sFasL (1 ng/ml) (Fig. 7E). Thus the ER stress response to Fas activation in the presence of SOD $1^{\mathrm{G} 93 \mathrm{~A}}$ is sufficient to explain the exacerbated sensitivity of ALS model motoneurons to activation of the Fas/NO pathway.

\section{Reductions in CRT act through induction of ER stress to trigger death of mSOD1 motoneurons}

Our results thus far showed that activation of Fas triggers a diminution of CRT and an increase in ER stress only in SOD1 ${ }^{\text {G93A }}$ motoneurons, and that these events lead to the selective vulnerability of ALS model motoneurons. Both changes occurred early ( $16 \mathrm{~h}$ of sFasL treatment), but the relation between the two remained unclear. To determine whether the CRT decrease was a consequence of ER stress activation or vice versa, we asked whether the ER stress inhibitor salubrinal could prevent the death of motoneurons induced by reduced CRT. We used two approaches to decrease CRT levels, shRNA to CRT or motoneurons from $\mathrm{crt}^{+/-}$embryos, and showed that salubrinal was indeed able to prevent cell death in both conditions (Fig. $8 A, B$ ). Thus activation of ER stress is necessary for death induced by reduced CRT.

We next asked whether, conversely, reductions in CRT were potentially involved in death induced by ER stress. To induce ER stress in vitro, we used the combined treatment of WT motoneurons with sublethal sFasL and tunicamycin shown to lead to motoneuron death (Fig. 7E). No reduction in CRT levels was detected (Fig. 8D). We also used sciatic nerve crush in 1-monthold mice to induce ER stress (but not death) in motoneurons in vivo (Saxena et al., 2009). Three days after nerve crush, ER stress monitored by BiP expression was clearly induced in motoneurons, but no decrease in CRT expression was observed (Fig. $8 E, F)$. Thus ER stress, which is itself sufficient to confer increased vulnerability on motoneurons, does not require CRT reduction to exert its effects on survival.

These data suggested that ER stress was downstream of CRT reduction. To further examine this we studied whether blocking ER stress in FasL-treated SOD1 ${ }^{\text {G93A }}$ motoneurons with salubrinal would prevent the decrease in CRT expression. This was not the case (Fig. 8C). Thus, in ALS model motoneurons, activation of the Fas pathway leads to reductions in CRT which in turn lead to ER stress. Each element of this pathway is necessary and sufficient to explain the exacerbated vulnerability of SOD ${ }^{\text {G93A }}$ motoneurons to this death mechanism.

\section{Discussion}

Protein misfolding and the cellular response and stress pathways it triggers are emerging as common themes in the study of neurodegenerative disease (Frost and Diamond, 2010). Misfolding may be caused by genetic mutations or may occur in response to external stressors or intracellular pathways. Mechanisms of cellular homeostasis initially compensate for such changes but progressively become unable to cope, leading to activation of catastrophic unfolded protein responses that trigger degeneration (Roth and Balch, 2011). A model was recently proposed in which multiple stressors converge to generate instability of proteostasis through vicious cycles of cell stress and protein misfolding (Saxena and Caroni, 2011). However, the mechanisms through which specific stressors interact with cellular stress path-

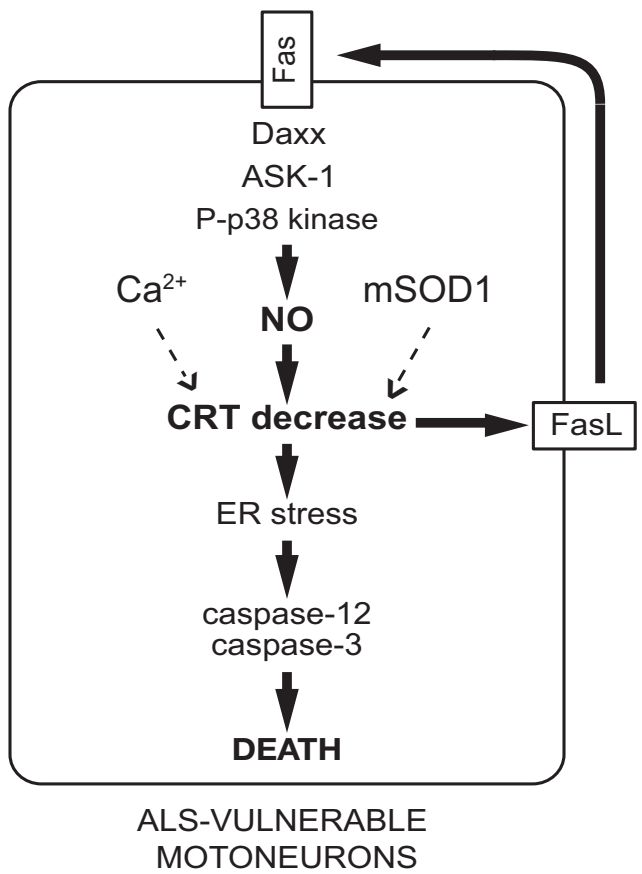

Figure 9. Model of CRT reduction and ER stress contribution to the death of SOD1 ${ }^{\text {G93A }}$ vulnerable motoneurons. While Fas activation leads in all motoneurons to activation of nNOS and NO production, only in mSOD1-vulnerable motoneurons does this activation induce a decrease in CRT leading to an ER stress response and death.

ways to generate neuronal class-specific degeneration remain to be determined.

Our data suggest a unifying hypothesis to explain the selective loss of vulnerable populations of motoneurons in the most widely studied animal model of ALS (Fig. 9). In mSOD1 but not WT motoneurons, activation of the motoneuron-specific Fas/NO pathway leads to reductions in levels of the ER chaperone CRT dependent on both NO production and increased cytoplasmic $\mathrm{Ca}^{2+}$. Reductions in CRT in turn trigger two processes leading to motoneuron death. First, they trigger further activation of Fas signaling through upregulation of Fas ligand, creating a selfamplifying vicious cycle. Second, they activate an ER stress response that, both in vitro and in vivo, plays a critical role in triggering degeneration and death of vulnerable motoneurons. This model explains the hypersensitivity of mSOD1 motoneurons to Fas activation and provides a crucial link between motoneuron-specific events and ER stress. CRT lies at the fulcrum of the two pathways, suggesting that if levels of CRT or its effectors can be maintained at normal levels, motoneuron degeneration in ALS may be slowed.

Reductions in CRT have been previously reported in neurodegenerative contexts. In particular, laser-captured motoneurons from presymptomatic $\mathrm{mSOD} 1$ mice showed a 30\% decrease in CRT mRNA (Perrin et al., 2005) and reduced CRT protein levels are apparent in symptomatic mSOD1 spinal cord (Teuling et al., 2007). Moreover, CRT is downregulated in cortical neurons of Alzheimer's patient brains (Taguchi et al., 2000) and in striatal neurons of hemiparkinsonian rats (Lessner et al., 2010). Although no functional studies were carried out, it is striking that ER stress is activated in all the above contexts (Wang and Takahashi, 2007; Lee et al., 2010; Lessner et al., 2010). Reductions in CRT may therefore play a general role in neurodegeneration.

Disruption of proteostasis has been proposed to underlie many of these neurodegenerative diseases. A recent stressor- 
threshold model (Saxena and Caroni, 2011) proposes that intrinsic genetic defects, extrinsic stressors, and instability of cellular homeostasis "combine to produce vicious cycles of increasing stressor load and misfolding protein accumulation, eventually causing age-related degeneration in selectively vulnerable neurons." In genetically predisposed mSOD1 motoneurons, we have identified the Fas/NO/CRT pathway as a motoneuron-specific stressor that increases the ER stress response to a threshold above which motoneurons undergo cell death. Even in the absence of mSOD1, chronic activation of the Fas/NO feedback loop could lead, by reducing levels of CRT, to the misfolding of other proteins including WT SOD1, which has been postulated to play a role in sporadic forms of ALS (Bosco et al., 2010).

The mechanism leading to reductions of CRT in vulnerable mSOD1 motoneurons is not known. Although Perrin et al. (2005) described a 30\% reduction in CRT messenger RNA in a microarray study, we could not detect a change in CRT expression in vivo by in situ hybridization (data not shown). While this discrepancy may be due to a lesser sensitivity of the in situ hybridization method compared with microarray detection, we favor the hypothesis of a post-translational decrease. Three main hypotheses that could lead to a diminution of CRT are discussed in the literature. One implicates changes in calcium homeostasis that have been shown to influence CRT expression (Corbett et al., 2000), and we demonstrated that chelating cytoplasmic calcium with BAPTA-AM prevents the decrease in CRT expression. Mislocalization of CRT constitutes another hypothesis. Indeed, mass spectrometry-liquid chromatography analysis of protein aggregates from end-stage mSOD1 mouse spinal cords revealed the presence of CRT together with $\mathrm{mSOD1}$, indicating a sequestration of CRT outside the ER (Bergemalm et al., 2010). Our own preliminary immunoprecipitation experiments confirm the CRT affinity to mSOD1 both in NSC34 cells transfected with either SOD $1^{\text {WT }}$ or SOD $1^{\mathrm{G} 93 \mathrm{~A}}$ and in spinal cord extracts of SOD $1^{\mathrm{WT}}$ and SOD $1{ }^{\mathrm{G} 93 \mathrm{~A}}$ mice at presymptomatic $(60 \mathrm{~d})$ and symptomatic (110 d) stages (data not shown). The third hypothesis is that CRT, as shown for mSOD1 (Urushitani et al., 2006), may be secreted from vulnerable motoneurons. A mechanism of secretion of CRT has been described in Jurkat cells treated with FasL or NO (Tarr et al., 2010). Unfortunately, using an ELISA test, we were unable to detect CRT release in the culture medium of motoneurons. Interestingly, a study aiming to identify biomarkers showed a doubling of CRT amount in ALS patients' peripheral blood mononuclear cells compared with controls (Nardo et al., 2011).

The association of CRT reductions with ER stress provides the first concrete link for the vulnerability to ALS of distinct subpopulations of motoneurons in vivo and in vitro. In vivo, three waves of ER stress, denervation, and motoneuron death have been described (Pun et al., 2006; Kanning et al., 2010, Saxena et al., 2009). In the most vulnerable motoneurons (Fast Fatigable) these events occur around, respectively, 38, 50, and $90 \mathrm{~d}$ and in resistant motoneurons (Fast Resistant), approximately 60, 80, and $110 \mathrm{~d}$. Finally, the most resistant motoneurons (Slow) show at $110 \mathrm{~d}$, an increase in stress markers such as PDI or Erp57 (Atkin, 2008), affecting probably only a few percent of the motoneurons. Each of these phases could be reflected in phases of CRT decrease. Reduced levels of CRT in vulnerable motoneurons in vivo also fit well with the lower calcium-buffering capacity of ALS-vulnerable motoneurons (Vanselow and Keller, 2000) and may be sufficient to explain the upregulation of ER stress selectively in vulnerable motoneurons (Saxena et al., 2009). In vitro, primary motoneuron cultures contain two populations with distinct susceptibility to ALS: the $50 \%$ whose death is triggered by
LIGHT, and the other half that are sensitive to the Fas/NO pathway (Aebischer et al., 2011). Unlike the Fas-responsive subpopulation, motoneurons targeted by LIGHT do not show altered properties when isolated from mSOD1 mice (Aebischer et al., 2011) and do not show reduced CRT (Fig. 1B). Therefore, although it would be premature to assign presumptive functional phenotypes to cultured embryonic motoneurons in vitro, it is striking that Fas-sensitive motoneurons in vitro and vulnerable motoneurons in vivo have in common a selective propensity to downregulate CRT and upregulate ER stress in the presence of mSOD1. Our in vitro data suggest that a qualitative difference sets them apart from more resistant populations (Fig. 9), potentially increasing the chances of selective therapeutic intervention.

Blocking ER stress by salubrinal treatment delayed onset and extended survival of mSOD1 mice by 20\% (Saxena et al., 2009), but side effects of salubrinal may have diminished the final impact of the treatment. There is likely a need to intervene more specifically in this pathway in motoneurons. Our data suggest that correcting the downregulation of CRT should be beneficial in ALS and perhaps other neurodegenerative diseases, and raise the possibility that CRT and its effectors may be potential therapeutic targets. However, CRT presents obvious challenges as a target since its ubiquitous overexpression has been shown to provoke heart block in mice (Nakamura et al., 2001). An alternative might be to express CRT selectively in neurons. However, our attempts to produce a viral vector overexpressing CRT to evaluate functional benefit in $\mathrm{mSOD} 1$ mice in vivo have encountered hurdles linked to cytotoxicity (data not shown), suggesting that levels would need to be very precisely maintained. A more promising long-term strategy might therefore be to intervene in the process through which CRT is downregulated. Despite these challenges, the identification of this ALS-specific pathway linking motoneuron degeneration to ER stress generates multiple candidate targets for future validation.

\section{References}

Aebischer J, Cassina P, Otsmane B, Moumen A, Seilhean D, Meininger V, Barbeito L, Pettmann B, Raoul C (2011) IFNgamma triggers a LIGHTdependent selective death of motoneurons contributing to the non-cellautonomous effects of mutant SOD1. Cell Death Differ 18:754-768.

Atkin JD, Farg MA, Walker AK, McLean C, Tomas D, Horne MK (2008) Endoplasmic reticulum stress and induction of the unfolded protein response in human sporadic amyotrophic lateral sclerosis. Neurobiol Dis 30:400-407.

Bergemalm D, Forsberg K, Srivastava V, Graffmo KS, Andersen PM, Brännström T, Wingsle G, Marklund SL (2010) Superoxide dismutase-1 and other proteins in inclusions from transgenic amyotrophic lateral sclerosis model mice. J Neurochem 114:408-418.

Boillée S, Vande Velde C, Cleveland DW (2006) ALS: a disease of motor neurons and their nonneuronal neighbors. Neuron 52:39-59.

Bosco DA, Morfini G, Karabacak NM, Song Y, Gros-Louis F, Pasinelli P, Goolsby H, Fontaine BA, Lemay N, McKenna-Yasek D, Frosch MP, Agar JN, Julien JP, Brady ST, Brown RH Jr (2010) Wild-type and mutant SOD1 share an aberrant conformation and a common pathogenic pathway in ALS. Nat Neurosci 13:1396-1403.

Breckenridge DG, Germain M, Mathai JP, Nguyen M, Shore GC (2003) Regulation of apoptosis by endoplasmic reticulum pathways. Oncogene 22:8608-8618.

Bruijn LI, Becher MW, Lee MK, Anderson KL, Jenkins NA, Copeland NG, Sisodia SS, Rothstein JD, Borchelt DR, Price DL, Cleveland DW (1997) ALS-linked SOD1 mutant G85R mediates damage to astrocytes and promotes rapidly progressive disease with SOD1-containing inclusions. Neuron 18:327-338.

Bruijn LI, Miller TM, Cleveland DW (2004) Unraveling the mechanisms involved in motor neuron degeneration in ALS. Annu Rev Neurosci 27:723-749.

Cashman NR, Durham HD, Blusztajn JK, Oda K, Tabira T, Shaw IT, Dah- 
rouge S, Antel JP (1992) Neuroblastoma x spinal cord (NSC) hybrid cell lines resemble developing motor neurons. Dev Dyn 194:209-221.

Corbett EF, Michalak KM, Oikawa K, Johnson S, Campbell ID, Eggleton P, Kay C, Michalak M (2000) The conformation of calreticulin is influenced by the endoplasmic reticulum luminal environment. J Biol Chem 275:27177-27185

Duplan L, Bernard N, Casseron W, Dudley K, Thouvenot E, Honnorat J, Rogemond V, De Bovis B, Aebischer P, Marin P, Raoul C, Henderson CE, Pettmann B (2010) Collapsin response mediator protein 4a (CRMP4a) is upregulated in motoneurons of mutant SOD1 mice and can trigger motoneuron axonal degeneration and cell death. J Neurosci 30:785-796.

Frey D, Schneider C, Xu L, Borg J, Spooren W, Caroni P (2000) Early and selective loss of neuromuscular synapse subtypes with low sprouting competence in motoneuron diseases. J Neurosci 20:2534-2542.

Frost B, Diamond MI (2010) Prion-like mechanisms in neurodegenerative diseases. Nat Rev Neurosci 11:155-159.

Gurney ME, Pu H, Chiu AY, Dal Canto MC, Polchow CY, Alexander DD, Caliendo J, Hentati A, Kwon YW, Deng HX et al. (1994) Motor neuron degeneration in mice that express a human $\mathrm{Cu}, \mathrm{Zn}$ superoxide dismutase mutation. Science 264:1772-1775.

Ilieva EV, Ayala V, Jové M, Dalfó E, Cacabelos D, Povedano M, Bellmunt MJ, Ferrer I, Pamplona R, Portero-Otín M (2007) Oxidative and endoplasmic reticulum stress interplay in sporadic amyotrophic lateral sclerosis. Brain 130:3111-3123.

Kanning KC, Kaplan A, Henderson CE (2010) Motor neuron diversity in development and disease. Annu Rev Neurosci 33:409-440.

Kikuchi H, Almer G, Yamashita S, Guégan C, Nagai M, Xu Z, Sosunov AA, McKhann GM 2nd, Przedborski S (2006) Spinal cord endoplasmic reticulum stress associated with a microsomal accumulation of mutant superoxide dismutase-1 in an ALS model. Proc Natl Acad Sci U S A 103:6025-6030.

Knee R, Ahsan I, Mesaeli N, Kaufman RJ, Michalak M (2003) Compromised calnexin function in calreticulin-deficient cells. Biochem Biophys Res Commun 304:661-666.

Langou K, Moumen A, Pellegrino C, Aebischer J, Medina I, Aebischer P, Raoul C (2010) AAV-mediated expression of wild-type and ALS-linked mutant VAPB selectively triggers death of motoneurons through a Ca2 +dependent ER-associated pathway. J Neurochem 114:795-809.

Lee JH, Won SM, Suh J, Son SJ, Moon GJ, Park UJ, Gwag BJ (2010) Induction of the unfolded protein response and cell death pathway in Alzheimer's disease, but not in aged Tg2576 mice. Exp MolMed42:386-394.

Lessner G, Schmitt O, Haas SJ, Mikkat S, Kreutzer M, Wree A, Glocker MO (2010) Differential proteome of the striatum from hemiparkinsonian rats displays vivid structural remodeling processes. J Proteome Res 9:4671-4687.

Magill CK, Tong A, Kawamura D, Hayashi A, Hunter DA, Parsadanian A, Mackinnon SE, Myckatyn TM (2007) Reinnervation of the tibialis anterior following sciatic nerve crush injury: a confocal microscopic study in transgenic mice. Exp Neurol 207:64-74.

Mesaeli N, Nakamura K, Zvaritch E, Dickie P, Dziak E, Krause KH, Opas M, MacLennan DH, Michalak M (1999) Calreticulin is essential for cardiac development. J Cell Biol 144:857-868.

Molinari M, Eriksson KK, Calanca V, Galli C, Cresswell P, Michalak M, Helenius A (2004) Contrasting functions of calreticulin and calnexin in glycoprotein folding and ER quality control. Mol Cell 13:125-135.

Nakamura K, Robertson M, Liu G, Dickie P, Nakamura K, Guo JQ, Duff HJ, Opas M, Kavanagh K, Michalak M (2001) Complete heart block and sudden death in mice overexpressing calreticulin. J Clin Invest 107:1245-1253.

Nardo G, Pozzi S, Pignataro M, Lauranzano E, Spano G, Garbelli S, Mantovani S, Marinou K, Papetti L, Monteforte M, Torri V, Paris L, Bazzoni G, Lunetta C, Corbo M, Mora G, Bendotti C, Bonetto V (2011) Amyotrophic lateral sclerosis multiprotein biomarkers in peripheral blood mononuclear cells. PLoS One 6:e25545.

Oyadomari S, Mori M (2004) Roles of CHOP/GADD153 in endoplasmic reticulum stress. Cell Death Differ11:381-389.
Perrin FE, Boisset G, Docquier M, Schaad O, Descombes P, Kato AC (2005) No widespread induction of cell death genes occurs in pure motoneurons in an amyotrophic lateral sclerosis mouse model. Hum Mol Genet 14:3309-3320.

Pun S, Santos AF, Saxena S, Xu L, Caroni P (2006) Selective vulnerability and pruning of phasic motoneuron axons in motoneuron disease alleviated by CNTF. Nat Neurosci 9:408-419.

Rao RV, Poksay KS, Castro-Obregon S, Schilling B, Row RH, del Rio G, Gibson BW, Ellerby HM, Bredesen DE (2004) Molecular components of a cell death pathway activated by endoplasmic reticulum stress. J Biol Chem 279:177-187.

Raoul C, Henderson CE, Pettmann B (1999) Programmed cell death of embryonic motoneurons triggered through the Fas death receptor. J Cell Biol 147:1049-1062.

Raoul C, Estévez AG, Nishimune H, Cleveland DW, deLapeyrière O, Henderson CE, Haase G, Pettmann B (2002) Motoneuron death triggered by a specific pathway downstream of Fas. potentiation by ALS-linked SOD1 mutations. Neuron 35:1067-1083.

Raoul C, Buhler E, Sadeghi C, Jacquier A, Aebischer P, Pettmann B, Henderson CE, Haase G (2006) Chronic activation in presymptomatic amyotrophic lateral sclerosis (ALS) mice of a feedback loop involving Fas, Daxx, and FasL. Proc Natl Acad Sci U S A 103:6007-6012.

Roth DM, Balch WE (2011) Modeling general proteostasis: proteome balance in health and disease. Curr Opin Cell Biol 23:126-134.

Saxena S, Caroni P (2011) Selective neuronal vulnerability in neurodegenerative diseases: from stressor thresholds to degeneration. Neuron 71:35-48.

Saxena S, Cabuy E, Caroni P (2009) A role for motoneuron subtypeselective ER stress in disease manifestations of FALS mice. Nat Neurosci 12:627-636.

Smith MJ, Koch GL (1989) Multiple zones in the sequence of calreticulin (CRP55, calregulin, HACBP), a major calcium binding ER/SR protein. EMBO J 8:3581-3586.

Taguchi J, Fujii A, Fujino Y, Tsujioka Y, Takahashi M, Tsuboi Y, Wada I, Yamada T (2000) Different expression of calreticulin and immunoglobulin binding protein in Alzheimer's disease brain. Acta Neuropathol 100:153-160.

Tarr JM, Young PJ, Morse R, Shaw DJ, Haigh R, Petrov PG, Johnson SJ, Winyard PG, Eggleton P (2010) A mechanism of release of calreticulin from cells during apoptosis. J Mol Biol 401:799-812.

Teuling E, Ahmed S, Haasdijk E, Demmers J, Steinmetz MO, Akhmanova A, Jaarsma D, Hoogenraad CC (2007) Motor neuron disease-associated mutant vesicle-associated membrane protein-associated protein (VAP) B recruits wild-type VAPs into endoplasmic reticulum-derived tubular aggregates. J Neurosci 27:9801-9815.

Urushitani M, Sik A, Sakurai T, Nukina N, Takahashi R, Julien JP (2006) Chromogranin-mediated secretion of mutant superoxide dismutase proteins linked to amyotrophic lateral sclerosis. Nat Neurosci 9:108-118.

Vanselow BK, Keller BU (2000) Calcium dynamics and buffering in oculomotor neurones from mouse that are particularly resistant during amyotrophic lateral sclerosis (ALS)-related motoneurone disease. J Physiol 525:433-445.

Verkhratsky A (2002) The endoplasmic reticulum and neuronal calcium signalling. Cell Calcium 32:393-404.

Wang HQ, Takahashi R (2007) Expanding insights on the involvement of endoplasmic reticulum stress in Parkinson's disease. Antioxid Redox Signal 9:553-561.

Wijesekera LC, Leigh PN (2009) Amyotrophic lateral sclerosis. Orphanet J Rare Dis 4:3.

Wong PC, Pardo CA, Borchelt DR, Lee MK, Copeland NG, Jenkins NA, Sisodia SS, Cleveland DW, Price DL (1995) An adverse property of a familial ALS-linked SOD1 mutation causes motor neuron disease characterized by vacuolar degeneration of mitochondria. Neuron 14:11051116. 